\title{
Control of Membrane Fouling in Organics Filtration Using Ce-Doped Zirconia and Visible Light
}

\author{
Fabrício Eduardo Bortot Coelho $^{1}\left[{ }^{\mathbb{D}}\right.$, Chiara Gionco ${ }^{1}{ }^{\circledR}$, Maria Cristina Paganini ${ }^{1,2}$, Paola Calza ${ }^{1}$ \\ and Giuliana Magnacca $1,2, *$ (D) \\ 1 Department of Chemistry, University of Torino, Via P.Giuria 7, 10125 Torino, Italy; \\ feabfc@gmail.com (F.E.B.C.); chiara.gionco@unito.it (C.G.); mariacristina.paganini@unito.it (M.C.P.); \\ paola.calza@unito.it (P.C.) \\ 2 NIS (Nanostructured Interfaces and surfaces), University of Torino, Via P.Giuria 7, 10125 Torino, Italy \\ * Correspondence: giuliana.magnacca@unito.it; Tel.: +390116707543
}

Received: 22 February 2019; Accepted: 28 March 2019; Published: 3 April 2019

\begin{abstract}
Membrane fouling has been a major issue in the development of more efficient water treatment processes. Specifically in surface waters filtration, organic matter, such as humic-like substances, can cause irreversible fouling. Therefore, this study evaluates the activity of a photocatalytic layer composed of Ce-doped zirconia nanoparticles in improving the fouling resistance during filtration of an aqueous solution of humic acid (HA). These nanoparticles were prepared by hydrothermal and sol-gel processes and then characterized. Before the filtration experiments, the photodegradation of HA catalyzed by Ce-doped zirconia nanoparticles in dispersion was studied. It was observed that the sol-gel prepared $\mathrm{Ce}-\mathrm{ZrO}_{2}$ exhibited higher $\mathrm{HA}$ removal in practically neutral $\mathrm{pH}$, achieving 93\% efficiency in $180 \mathrm{~min}$ of adsorption in the dark followed by 180 min under visible-light irradiation using light-emitting diodes (LEDs). Changes in spectral properties and in total organic carbon confirmed HA degradation and contributed to the proposal of a mechanism for HA photodegradation. Finally, in $\mathrm{HA}$ filtration tests, $\mathrm{Ce}-\mathrm{ZrO} 2$ photocatalytic membranes were able to recover the flux in a fouled membrane using visible-light by degrading HA. The present findings point to the further development of anti-fouling membranes, in which solar light can be used to degrade fouling compounds and possibly contaminants of emerging concern, which will have important environmental implications.
\end{abstract}

Keywords: fouling; humic acid; zirconium dioxide; photocatalysts; cerium; visible light; LED; membrane filtration

\section{Introduction}

As water scarcity becomes more severe and the emission of contaminants of emerging concern (CEC) increases, it is critical to develop more effective and less energy-consuming treatments for drinking and wastewaters [1,2]. In this way, membrane filtration attracts great attention since it has high retention of contaminants [3], and it has already become the established technique for several processes, such as drinking water production from seawater desalination [4]. However, in the operation of membrane systems, fouling is still a major issue, since it decreases the water flux and lifespan of the membranes considerably [2,5-8]. As a consequence, costs and energy consumption increase, which limits large scale industrial applications of membranes $[2,9,10]$. There are several processes that cause fouling, such as biological growth, scaling (precipitation of inorganic salts), solid particles, and organic substances (e.g., oils, natural organic matter) [5]. Among the possible sources, the irreversible fouling caused by the adsorption of organic dissolved matter (e.g., humic-like substances) into the membrane surface and pores, is pointed to as a critical issue [11-14]. Indeed, it usually requires chemical cleaning 
to recover the original water flux [15]. Therefore, to avoid pre-treatments of the feed stream (e.g., ozonation, flocculation) or membrane cleaning processes (e.g., back pulsing, air scrubbing), a more sustainable approach to controlling fouling would be to functionalize membranes with polymers or nanomaterials, such as carbon nanotubes, zeolite, and iron oxide. This functionalization could act using two different mechanisms. Traditionally, this functionalization has been applied to modify the charge and hydrophobicity of the membrane surface, preventing the adsorption/adhesion of fouling substances [10,16-20]. In a more recent approach, membrane functionalization was added to a photocatalytic layer, which is responsible for the degradation of organic compounds and, therefore, prevents the fouling [21]. Mendret et al. [1] coated a flat-sheet $\alpha-\mathrm{Al}_{2} \mathrm{O}_{3}$ membrane with $\mathrm{TiO}_{2}$ and obtained a composite membrane capable of degrading Acid Orange 7 under UV irradiation, preventing flux decrease under filtration.

However, despite $\mathrm{TiO}_{2}$ 's unique photocatalytic activity and stability [22], this material requires photons in the UV frequencies to create the electron-hole photo-induced separation (i.e., excitation from the valence band (VB) to the conduction band (CB), separated by about $3.2 \mathrm{eV}$ ). Hence, this fact practically excludes the use of sunlight as an energy source for $\mathrm{TiO}_{2}$. To overcome this limitation, several modifications of $\mathrm{TiO}_{2}$ have been studied, such as its doping with transition-metal ions [23], non-metal atoms [24], or supported metal nanoparticles having plasmonic effects [25]. In addition, coupling two different semiconductors also resulted in success [26]. All these systems constitute the second-generation photoactive materials based on titanium dioxide. On the other hand, semiconductors with higher band gap values imply higher electrochemical potentials of excited electrons and holes, which can lead to more effective photocatalytic activity [27]. Therefore, the continuous pursuit of active photocatalysts that work under visible light has addressed the research to develop the third generation of materials not based on $\mathrm{TiO}_{2}$ [4,28]. Zirconium dioxide has been rarely applied in photocatalysis because of its wide band gap (ca. $5.0 \mathrm{eV}$ ); although some reports are available concerning photo-oxidation of chemicals [29-31] and water photosplitting [32]. On the other hand, the band energy levels of $\mathrm{ZrO}_{2}$ are suitable for photocatalytic applications because the lowest potential of the $\mathrm{CB}$ is $-1.0 \mathrm{~V}$ (vs. normal hydrogen electrode (NHE), pH 0 ), much more negative than that of $\mathrm{TiO}_{2}$ anatase $(-0.1 \mathrm{~V})$, whereas, the highest potential of the $\mathrm{VB}$ is $+4.0 \mathrm{~V}$, more positive than that of $\mathrm{TiO}_{2}(+3.1 \mathrm{~V})$. Therefore, $\mathrm{ZrO}_{2}$ energetic photo-induced electrons and holes are able to generate reactive oxygen species (ROS), with a great potential to degrade organic compounds or to oxidize the organic molecules directly [33]. In recent works from our group [33,34], doping $\mathrm{ZrO}_{2}$ with cerium has introduced intra band gap states between zirconia VB and CB, allowing the new catalyst to absorb visible light through a double jump mechanism. These findings were relevant since they indicated that solar light could be used as a light source for the $\mathrm{Ce}-\mathrm{ZrO}_{2}$ photocatalytic degradation of organic compounds. Such a process could then be applied in the control of fouling by degrading organic fouling molecules, such as humic-like substances, but also degrading contaminants of emerging concern, which would have important environmental implications.

In the present work, Ce-doped $\mathrm{ZrO}_{2}$ was synthesized by hydrothermal and sol-gel processes. The nanopowders obtained were then characterized in terms of crystal structure, morphology, surface area, porosity, surface charge, light absorption, photo-induced charge separation, and ROS generation. Next, since there are no data on the literature about humic acid (HA) photodegradation with Ce-doped zirconia, batch experiments were performed to evaluate the photocatalytic activity of the $\mathrm{Ce}-\mathrm{ZrO}_{2}$ nanoparticles dispersed in humic acid aqueous solutions under visible light irradiation. Adsorption isotherms were determined and the effects of several parameters (e.g., HA concentration, catalyst dosage, and $\mathrm{pH}$ ) on HA removal where investigated. The Langmuir-Hinshelwood model was used for kinetic modeling. The changes in spectral properties and in total organic carbon (TOC) were analyzed, confirming that HA is actually degraded during the photocatalytic process. A mechanism for HA photodegradation is proposed. Finally, Ce-doped zirconia nanoparticles were supported in filter papers to produce prototypes of a photocatalytic membrane with improved anti-fouling resistance. 


\section{Materials and Methods}

\subsection{Synthesis and Characterization of Photocatalysts}

In the present work, hydrothermal and sol-gel processes were evaluated to prepare zirconia doped with $0.5 \%$ molar of cerium. In the hydrothermal synthesis, an aqueous solution of $1.0 \mathrm{M}$ of $\mathrm{ZrOCl}_{2} \cdot 8 \mathrm{H}_{2} \mathrm{O}$ (CAS 13520-92-8, purity >98\%) and $0.005 \mathrm{M} \mathrm{Ce}\left(\mathrm{SO}_{4}\right)_{2}(\mathrm{CAS} 13454-94-9$, essay $>99.9 \%)$ were mixed and kept under stirring at room temperature. Then, the $\mathrm{pH}$ was adjusted to 11 by using an aqueous solution of $4.0 \mathrm{M}$ of $\mathrm{NaOH}$. The resulting solution and the precipitates were then transferred into a $125 \mathrm{~mL}$ Teflon-lined stainless steel autoclave, $70 \%$ filled, which was heated at $175{ }^{\circ} \mathrm{C}$ for $15 \mathrm{~h}$ in an oven. The precipitates were, hence, centrifuged and washed three times with deionized water, then dried at $70{ }^{\circ} \mathrm{C}$. This sample was labelled as $\mathrm{Ce}-\mathrm{ZrO}_{2}-\mathrm{HYD}$. For the sol-gel synthesis, $5 \mathrm{~mL}$ of zirconium propoxide $\mathrm{Zr}\left(\mathrm{OC}_{3} \mathrm{H}_{7}\right)_{4}$ (CAS 23519-77-9, 70\% wt.) were mixed with $5 \mathrm{~mL}$ of 2-propanol. Then, $28 \mathrm{mg}$ of $\mathrm{Ce}\left(\mathrm{NH}_{4}\right)_{2}\left(\mathrm{NO}_{3}\right)_{6}$ (CAS 16774-21-3, purity $>98.5 \%$ ), dissolved in $5 \mathrm{~mL}$ of double distilled water, was added to the first solution to start hydrolysis. The resulting gel was kept overnight at room temperature and then dried at $80^{\circ} \mathrm{C}$. After aging at room temperature for 10 days, the xerogel was calcined in a muffle furnace at $500{ }^{\circ} \mathrm{C}$ in air for $4 \mathrm{~h}$. This sample was labelled $\mathrm{Ce}-\mathrm{ZrO}_{2}$-SG. For comparison, pure zirconia samples were prepared by the same hydrothermal and sol-gel procedures, without the addition of cerium, and named $\mathrm{ZrO}_{2}-\mathrm{HYD}$ and $\mathrm{ZrO}_{2}-\mathrm{SG}$, respectively. All aqueous solutions were prepared using ultrapure water Milli- $\mathrm{Q}^{\mathrm{TM}}$ (Millipore, Burlington, MA, USA). All chemicals were bought from Sigma-Aldrich (St. Louis, MO, USA) and used without further purification.

Powder X-rays diffraction (XRD) patterns were obtained with the diffractometer PW3040/60 X'Pert PRO MPD (PANalytical, Almelo, The Netherlands), operating at $45 \mathrm{kV}, 40 \mathrm{~mA}$, with a Cu K $\alpha$ radiation source $\left(\lambda=1.5418 \AA\right.$ ) and a Bragg Brentano geometry over the range $10^{\circ}<2 \theta<80^{\circ}$.

Nitrogen adsorption-desorption isotherms were obtained (Micromeritics ASAP 2020) for the determination of surface area, using the Brunauer-Emmett-Teller (BET) model, and pore size distribution, using the Barrett-Joyner-Halenda ( $\mathrm{BJH}$ ) model applied on the desorption branch of the isotherms. Before the adsorption run, all the samples were outgassed at $150{ }^{\circ} \mathrm{C}$ for $8 \mathrm{~h}$.

Diffuse reflectance spectroscopy (DRS) data were recorded in the 200 to $800 \mathrm{~nm}$ range using the spectrometer Cary 5000 (Varian, Palo Alto, CA, USA), coupled with an integration sphere for diffuse reflectance studies, using Carywin-UV/scan software. A sample of Polytetrafluoroethylene (PTFE) with $100 \%$ reflectance was used as the reference. The optical band gap energy has been calculated from the Tauc plot.

Zeta potential measurements were performed on a Zetasizer Nano ZS (Malvern Instrument, Malvern, UK) using principles of laser Doppler velocitometry and phase analysis light scattering (M3-PALS technique). Zero point one percent weight/volume suspensions of nanoparticles were prepared with a $\mathrm{NaCl} 0.01 \mathrm{M}$ aqueous solution and ultrasonicated for $10 \mathrm{~min}$ before the analysis.

\subsection{Photocatalytic Experiments}

Humic acid solutions were prepared by dissolving humic acid sodium salt (CAS 68131-04-4, Sigma Aldrich, $\mathrm{MP}>300{ }^{\circ} \mathrm{C}$ ) and then adjusting the $\mathrm{pH}$ to the desired value using aqueous solutions of $\mathrm{NaOH}$ and $\mathrm{HCl}$.

For the determination of the adsorption isotherms, the zirconia powder was added to the HA solutions, and the $\mathrm{pH}$ was then adjusted to 6.5. Then, the mixture was kept stirring in the dark for $24 \mathrm{~h}$. The initial humic acid concentration $\left([H A]_{0}\right)$ was varied between 5 and $20 \mathrm{mg} \cdot \mathrm{L}^{-1}$ and the zirconia dosage between 0.1 and $1.0 \mathrm{~g} \cdot \mathrm{L}^{-1}$.

In the photocatalytic experiments, a specific amount of the zirconia nanoparticles was added to the HA solution to achieve the desired catalyst dosage. As a reactor, a $100 \mathrm{~mL}$ borosilicate glass beaker was used. The $\mathrm{pH}$ was then adjusted to the desired value. Before irradiation, the mixture was kept under stirring in the dark for $3 \mathrm{~h}$ to achieve HA adsorption equilibrium. Then, the mixture 
was irradiated with visible light for more $3 \mathrm{~h}$ under stirring, without any injection of gas. Samples were collected in specific intervals of time. The source of light was a home-built apparatus, consisting of a series of red-green-blue (RGB) light-emitting diodes (LEDs) disposed in a cylindrical support (diameter $11 \mathrm{~cm}$ ), in which the beaker with the suspension was placed in the center. The LEDs' emission spectrum is composed of three peaks with maximum intensities around 455, 530, and $625 \mathrm{~nm}$, all in the visible range. The total power of the system was $20 \mathrm{~W}$, and the irradiance at the center of the cylinder was $30 \mathrm{~W} \cdot \mathrm{m}^{-2}$ (measured with the HD 2302.0 Light meter, Delta OHM). Next, for determining the HA concentration in the solution, the samples were centrifuged at 11,000 rpm for $10 \mathrm{~min}$. The UV-Vis spectra of the supernatants were then recorded using the spectrophotometer UVIKON 930 (Kontron Instruments, Zurich, Switzerland), in the wavelength range of 200 to $700 \mathrm{~nm}$. The concentration of humic acid was then calculated by the UV absorbance at $254 \mathrm{~nm}$. This method has been extensively applied for determining the HA concentration [21,35-38], and it can be correlated to the total organic carbon (TOC) value through a calibration curve $[39,40]$. TOC measurements were carried out with

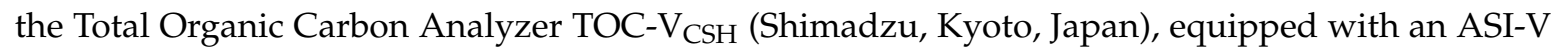
auto-sampler, and fed with zero-grade air. The TOC was determined as the difference between total carbon (TC) and inorganic carbon (IC).

The stability of $\mathrm{Ce}-\mathrm{ZrO}_{2}$-SG nanoparticles was investigated in multiple HA photodegradation cycles. For that, after each 180 min cycle, a concentrated HA solution was added to achieve the initial HA concentration and keep the same initial catalyst dosage $\left(1 \mathrm{~g} \cdot \mathrm{L}^{-1}\right)$. Then, the dispersion was irradiated again for another $180 \mathrm{~min}$. No treatment, such as washing or centrifugation, was performed between the cycles.

\subsection{Preparation of the Photocatalitic Membrane and Fouling Tests}

For the preparation of the photocatalytic membranes, $100 \mathrm{mg}$ of $\mathrm{Ce}-\mathrm{ZrO}_{2}-\mathrm{SG}$ nanoparticles were dispersed in $100 \mathrm{~mL}$ of distilled water and ultrasonicated for $10 \mathrm{~min}$. Then, the dispersion was vacuum-filtered to settle the particles in a filter paper support (bleached Kraft paper for sterile packaging applications), with an active filtration area of $12.6 \mathrm{~cm}^{2}$. Before the addition of the particles, filter papers were treated with acetone and ammonium hydroxide for cleaning purposes.

Filtration tests were performed in a cross-flow filtration setup made in poly(methyl methacrylate) (PMMA) with a polystyrene window for light irradiation (Figure 1). The height of liquid between the membrane and the window was $3 \mathrm{~cm}$. An aqueous solution of humic acid $\left(15 \mathrm{mg} \cdot \mathrm{L}^{-1}, \mathrm{pH} 7\right)$ was used as a feed stream. The feed reservoir was connected to the diaphragm pump STEPDOS 08 $\mathrm{S}$ (KNF Flodos, Sursee, Switzerland) to keep a cross flow rate of $3.4 \mathrm{~L} \cdot \mathrm{h}^{-1}$. The mass of permeate obtained was continuously measured with the digital balance KERN 572 (KERN \& SOHN Balingen, Germany), and the concentration of humic acid was measured using the UV-Vis spectrophotometer Cary 300 Scan (Varian, Palo Alto, CA, USA). Two sets of fouling experiments were performed using the photocatalytic membranes. In the first set, two separated tests were done, one in the dark and other under irradiation. In the second set, the filtration was performed initially under dark, until the membrane was fouled, and the flux stabilized; then, the filtration was continued under light irradiation. As light source it was used a $18 \mathrm{~W}$ white LED lamp, which has a color temperature of $6500 \mathrm{~K}$ and no UV/IR emission, as indicated by the manufacturer (WELLMAX, Shanghai, China). The light was positioned just above the window, providing an irradiance of $1000 \mathrm{~W} \cdot \mathrm{m}^{-2}$. 


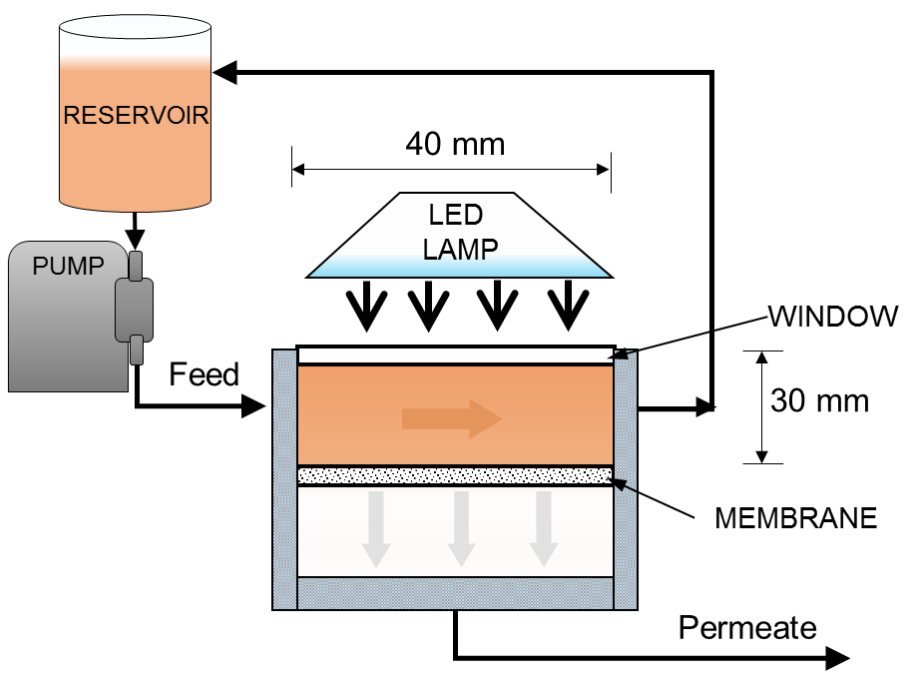

Figure 1. Cross-flow filtration setup for fouling experiments with light irradiation.

\section{Results and Discussion}

\subsection{Characterization of Photocatalysts}

In agreement with previously reported characterization procedures $[27,33,34,41,42]$, the structure of the resulting phases, obtained via both syntheses, is a mixture of monoclinic and tetragonal $\mathrm{ZrO}_{2}$ (Figure S1). In both pure and doped oxides, the monoclinic phase presents some degree of anisotropy, as suggested by the variable width of the diffraction peaks [34,42]. None of the samples shows the presence of diffraction peaks related to the formation of $\mathrm{CeO}_{2}$ phases, indicating that cerium was successfully inserted in the $\mathrm{ZrO}_{2}$ matrix.

To investigate the surface area and porous structure of the doped zirconia samples, nitrogen adsorption/desorption analyses were performed. The BET method was used to determine the specific surface areas of the samples (reported in Table 1). As shown in Figure 2, both samples show type IV IUPAC (International Union of Pure and Applied Chemistry) isotherms with a hysteresis loop type $H 3$ (typically observed in aggregates of plate-like particles giving rise to slit-shaped pores) in the relative pressure $\left(P / P_{0}\right)$ range of 0.8 to 1.0 , which indicates the presence of large mesoporosity. However, it is quite probable that this porosity is due to void space given by interparticle porosity, given by aggregation of primary particles $[43,44]$ rather than intraparticle porosity. The explanation relies on the fact that to accommodate such large pores, bigger particles are required, which are not present in the samples, as suggested by the crystallite size (10-20 nm of diameter) and TEM images obtained in a previous work [33]. Regarding the specific surface area, the doped zirconia prepared by sol-gel synthesis exhibits a higher $S_{B E T}$ than the hydrothermally synthesized sample (Table 1), whereas, the addition of Ce does not cause a substantial modification in the morphology of hydrothermal (HYD) sample but causes a decrease of the specific surface area of the SG sample from 150 to $70 \mathrm{~m}^{2} \cdot \mathrm{g}^{-1}$.

Table 1. Specific surface areas $\left(\mathrm{S}_{\mathrm{BET}}\right)$ of pure and Ce-doped zirconia samples.

\begin{tabular}{cc}
\hline Sample & $\mathrm{S}_{\text {BET }}\left[\mathbf{m}^{\mathbf{2}} \cdot \mathbf{g}^{\mathbf{- 1}}\right]$ \\
\hline $\mathrm{ZrO}_{2}-\mathrm{HYD}$ & $44 \pm 4$ \\
$\mathrm{Ce}-\mathrm{ZrO}_{2}$-HYD & $49 \pm 5$ \\
$\mathrm{ZrO}_{2}-\mathrm{SG}$ & $150 \pm 15$ \\
$\mathrm{Ce}-\mathrm{ZrO}_{2}-\mathrm{SG}$ & $70 \pm 7$ \\
\hline
\end{tabular}




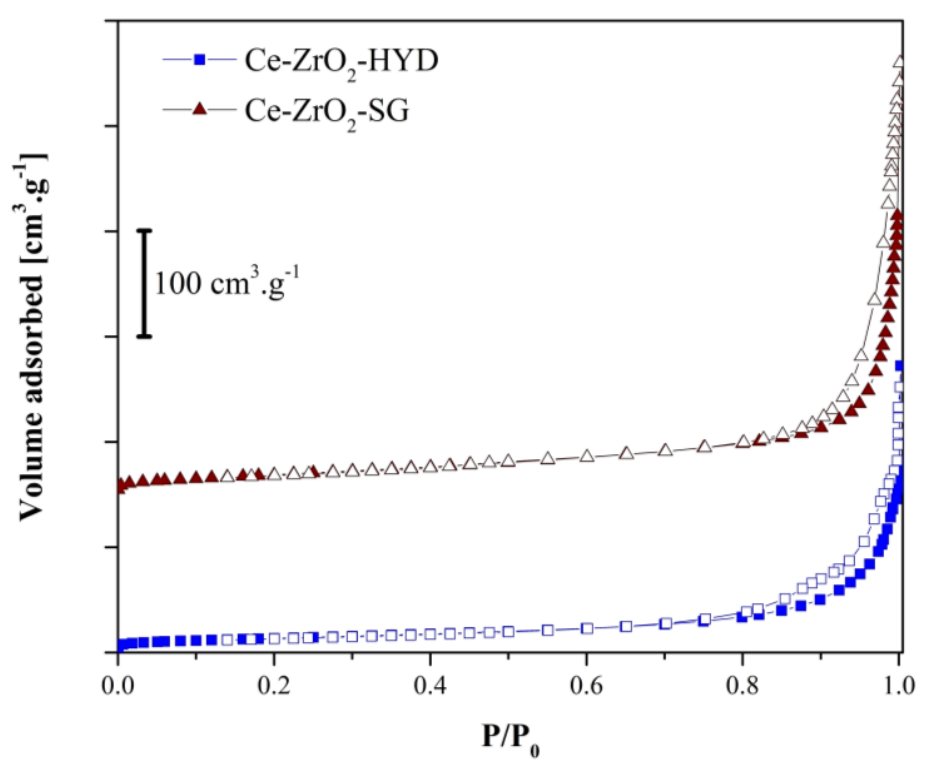

Figure 2. $\mathrm{N}_{2}$ adsorption/desorption isotherms of $\mathrm{Ce}-\mathrm{ZrO}_{2}$ prepared by sol-gel (SG) and hydrothermal (HYD) processes.

To evaluate the surface charge of the Ce-doped zirconia samples in aqueous solutions, since it is closely related to the adsorption properties, the zeta potential of the samples was measured at several $\mathrm{pH}$ values, as shown in Figure 3. It can be observed that both hydrothermally and sol-gel prepared samples exhibit a negative charge in a wide range of $\mathrm{pH}(4-9)$, which indicates that the surface of the zirconia, as expected, is rich in $\mathrm{OH}$ groups (vide FTIR spectra, Figure S2). The zirconia OH groups can be classified as terminal or bridged; terminal $\mathrm{OH}$ is a Brønsted base site, while bridged $\mathrm{OH}$ is a Brønsted acid site resulting from the protonation of bridging oxygen ions [45]. Using titration methods, Sahu and Rao [46] observed the prevalence of acid sites on the zirconia surface, which explains the highly negative zeta potential values measured in the present work when increasing the $\mathrm{pH}$. These authors also stated that the distribution of active sites is closely related to the number of defects, which is mainly affected by preparation methods (e.g., calcination temperature, wet or dry synthesis). This fact can help to understand why the sol-gel prepared $\mathrm{Ce}-\mathrm{ZrO}_{2}$ has less negative zeta potential values than the hydrothermal one. In fact, the last step in the sol-gel process is calcination at $500{ }^{\circ} \mathrm{C}$, which reduces the number of $\mathrm{OH}$ groups in the particles surface.

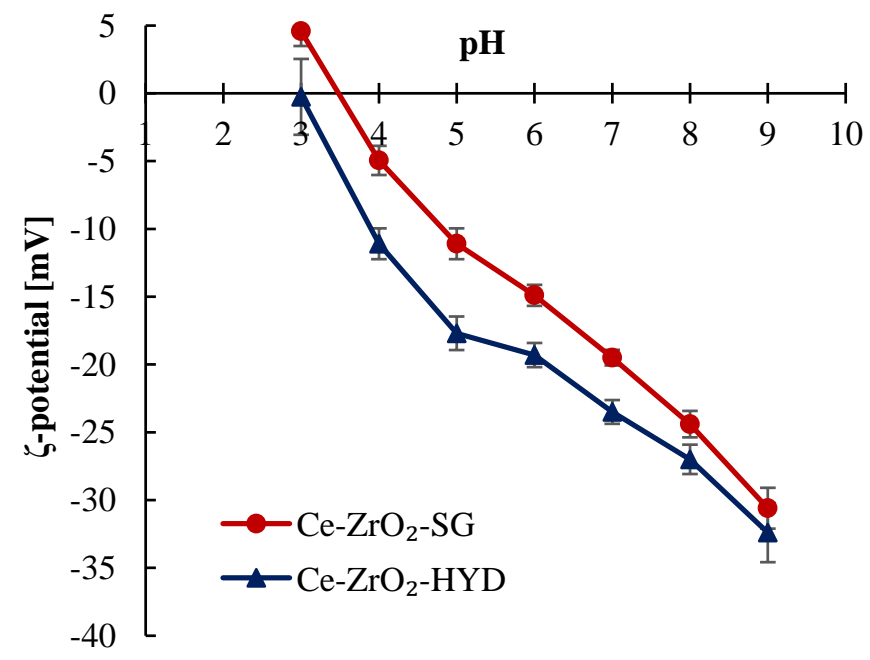

Figure 3. Zeta potential as a function of $\mathrm{pH}$ for the $\mathrm{Ce}-\mathrm{ZrO}_{2}$ prepared by hydrothermal (HYD) and sol-gel (SG) processes. 
The interest in these materials in the present paper deals with their optical absorption properties, which were investigated by diffuse reflectance spectroscopy (DRS). As observed in Figure S3, the addition of a small amount of cerium dramatically affects the optical properties of the materials, promoting a red-shift in the absorption spectra. An absorption shoulder, centered at ca. $300 \mathrm{~nm}$, with a tail in the visible region is clearly observed in both hydrothermal and sol-gel Ce-doped samples, but it is more pronounced in the hydrothermal sample, as also observed previously [34]. In regards to the band gap transitions, two $E_{\text {gap }}$ values were reported, 5.2 and 3.6-3.7 [33,47], the first value associated with the fundamental $\mathrm{VB} \rightarrow \mathrm{CB}$ transition of $\mathrm{ZrO}_{2}$ (unaffected by the Ce doping), the second one due to the absorption band associated to the $\mathrm{O} 2 \mathrm{p} \rightarrow \mathrm{Ce} 4 \mathrm{f}$ charge transfer transition [41]. Therefore, this result indicates that the prepared Ce-doped oxides have the potential to work as photocatalysts under solar light irradiation.

\subsection{Adsorption Isotherms}

Humic acid is a large molecule $(30-50 \mathrm{kDa})$ with several hydrophilic functional groups, such as $\mathrm{COOH}$ and $\mathrm{OH}$, but also with large hydrophobic moieties, some of them consisting of aromatic rings [10]. Given the chemical structure, it can interact very easily and strongly with ceramic materials which are rich in $\mathrm{OH}$ groups via ionic, electrostatic, and hydrogen bonding. For our purposes, i.e., the study of antifouling materials for ceramic membrane production, humic substances are interesting for at least two reasons, as already discussed in the Introduction section: on the one hand, several substances present in natural water have structure and behaviors similar to those of humic substances and the study of the fate of these compounds in filtration units can allow to predict how long a membrane can resist the fouling process before the regeneration; on the other hand, humic substances can mimic the fouling substances found in filters after separation of organic molecule (i.e., pollutants) from aqueous matrices. As the regeneration of a membrane requires time and economic burdens, it would be highly convenient to produce a membrane with antifouling properties, which can be done using a material with no affinity towards fouling substances (hydrophobic), or producing a membrane where the fouling can be removed by irradiation in the presence of a proper photocatalyst. If the photocatalytic material is used to fabricate the membrane, one can imagine producing an antifouling membrane with potentially infinite working time and no necessity of cyclic regeneration. Achieving the objective, the functional membrane prepared will be neither subjected to lack of permeation during use and have several advantages for the industrial application of the device.

The photocatalyst we would like to use is the Ce-doped zirconia, whose activation upon visible light irradiation can allow to obtain an integrated system for filtration of pollutants and consequent abatement of the retentate in solar plants.

Since the Ce-doped zirconia nanoparticles are rich in-OH groups (vide FTIR spectra, Figure S2), a considerable adsorption of HA into the particles surface is expected, but it is known in the literature that often the adsorption is only the first step to obtain the photocatalytic abatement of the adsorbed substrates $[22,44]$. To evaluate the extent of $\mathrm{HA}$ adsorption at the surface of $\mathrm{Ce}-\mathrm{ZrO}_{2}$ nanoparticles, a series of experiments were performed to obtain the related adsorption isotherms (in the dark, $\left.\mathrm{pH} 6.5, \mathrm{~T}=25 \pm 3{ }^{\circ} \mathrm{C}\right)$. Then, the Langmuir model, which assumes monolayer adsorption onto a surface containing a finite number of adsorbing sites, and the Freundlich model, which assumes heterogeneous surface energies, were evaluated to fit the experimental data (Figure S4). Only the Langmuir isotherm presented a good correlation $\left(\mathrm{R}^{2}>0.99\right)$ with the experimental data. Therefore, the relevant data of Langmuir fit are reported in Table 2. This can be explained by the fact that HA has a highly negative charge at neutral $\mathrm{pH}$ [48]; then, $\mathrm{HA}$ is mainly adsorbed in a monolayer rather than in multilayers due to the large electrostatic repulsion between the adsorbed molecules and the molecules to be adsorbed [49]. The Langmuir equation is expressed as:

$$
\frac{C_{e}}{q}=\frac{1}{q_{e} K_{L}}+\frac{C_{e}}{q_{e}}
$$


Table 2. Parameters for the humic acid (HA) adsorption isotherms in the doped zirconia samples.

\begin{tabular}{cccc}
\hline \multirow{2}{*}{ Sample } & \multicolumn{3}{c}{ Langmuir Adsorption Model } \\
\cline { 2 - 4 } & $\mathbf{q}_{\mathbf{e}}\left[\mathbf{m g} \cdot \mathbf{g}^{\mathbf{- 1}}\right]$ & $\mathbf{k}_{\mathbf{L}}$ & $\mathbf{R}^{\mathbf{2}}$ \\
\hline $\mathrm{Ce}-\mathrm{ZrO}_{2}$-HYD & 9.3 & 0.36 & 0.998 \\
$\mathrm{Ce}-\mathrm{ZrO}_{2}$-SG & 12.3 & 0.74 & 0.997 \\
\hline
\end{tabular}

In this equation, $C_{e}$ is soluble material concentration $\left[\mathrm{mg} \cdot \mathrm{L}^{-1}\right], q_{e}$ is the adsorption capacity $\left[\mathrm{mg} \cdot \mathrm{g}^{-1}\right]$, $\mathrm{q}$ is the adsorption rate $\left[\mathrm{mg} \cdot \mathrm{g}^{-1}\right]$, and $K_{L}$ is Langmuir equation constant.

From Table 2, it can be observed that the sol-gel zirconia has a higher HA adsorption capacity than the hydrothermal one. One possible explanation for this fact is the higher specific surface area of the sol-gel zirconia (Table 1), which implies a higher number of active sites available for the HA adsorption. In addition, the sol-gel prepared $\mathrm{ZrO}_{2}$ has a lower negative surface charge than the hydrothermal one $(\zeta=-17.2$ at $\mathrm{pH} 6.5 \mathrm{vs}$. $-21.4 \mathrm{mV})$; therefore, the repulsion between the negatively charged humic acid and the surface is less intense, favoring the adsorption of HA. To corroborate this statement, it can be shown how the $\mathrm{pH}$ affects $\mathrm{HA}$ adsorption on $\mathrm{Ce}-\mathrm{ZrO}_{2}-\mathrm{SG}$ particles (Figure 4). At pH 5.0, the negative surface charge of zirconia is lower (Figure 3), which reduces the electrical repulsion by the negatively charged HA molecules, favoring their adsorption. However, it should be noticed that, at $\mathrm{pH}$ values lower than 5.5, the solubility of HA decreases considerably [50], which also explains the increased HA apparently adsorbed in more acidic solutions. Moreover, in acid medias, humic acid molecules may aggregate to the extent of forming micelle-like structures [51]. On the other hand, at higher $\mathrm{pH}$ values, humic acid carboxylic and phenolic group deprotonate, increasing the HA negative charge [48,51]. Consequentially, the HA repulsion exerted by zirconia nanoparticles is greater.

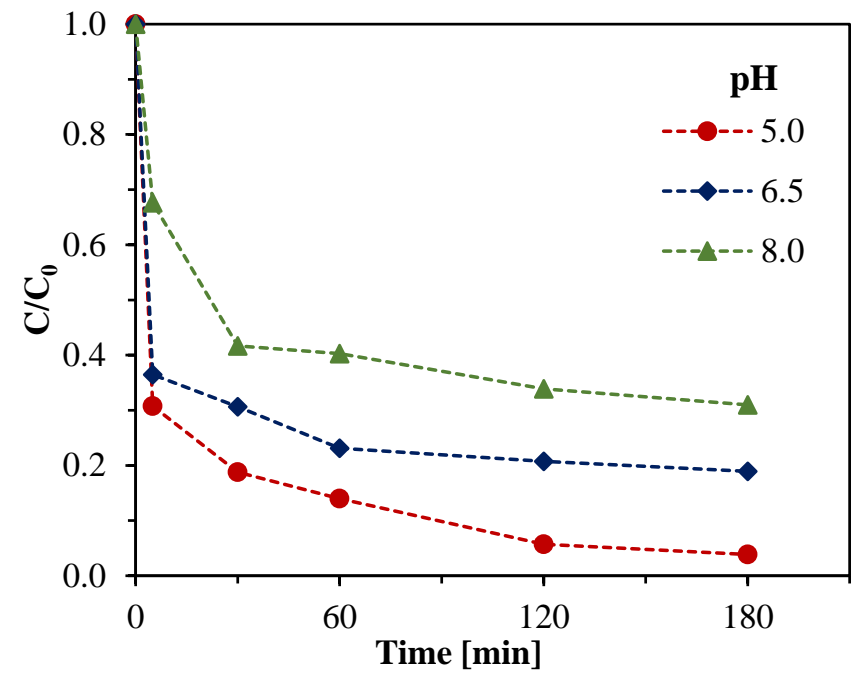

Figure 4. Adsorption of humic acid on $\mathrm{Ce}-\mathrm{ZrO}_{2}-\mathrm{SG}$ (under dark, $\mathrm{T}=25 \pm 3{ }^{\circ} \mathrm{C},[\mathrm{HA}]_{0}=10 \mathrm{mg} \cdot \mathrm{L}^{-1}$, adsorbent dosage $\left.=1 \mathrm{~g} \cdot \mathrm{L}^{-1}\right)$.

The values obtained for the maximum adsorption using doped zirconia are in agreement with other adsorbents. A value of $8 \mathrm{mg} \cdot \mathrm{g}^{-1}$ was reported by Ferro-Garcia et al. [52] for a commercial activated carbon. For zeolites, maximum HA adsorption capacity values of 8.7 and $13 \mathrm{mg} \cdot \mathrm{g}^{-1}$ were obtained by Moussavi et al. [53] and Coppola et al. [54], respectively. In comparison with other photocatalysts, Liu et al. [49] obtained an adsorption capacity of $5.9 \mathrm{mg} \cdot \mathrm{g}^{-1}$ using zeolite $/ \mathrm{TiO}_{2}$ particles, whereas, Sun and Lee [48] reported $8 \mathrm{mg} \cdot \mathrm{g}^{-1}$ for $\mathrm{TiO}_{2}$ microspheres. 


\subsection{Photocatalytic Activity}

To evaluate if the prepared zirconia nanoparticles would be able to degrade humic acid in a photocatalytic process, a series of experiments was done with $1 \mathrm{~g} \cdot \mathrm{L}^{-1}$ of pure and doped $\mathrm{ZrO}_{2}$. An experiment without any powder was also performed to check the direct photolysis of HA. Results are shown in Figure 5.

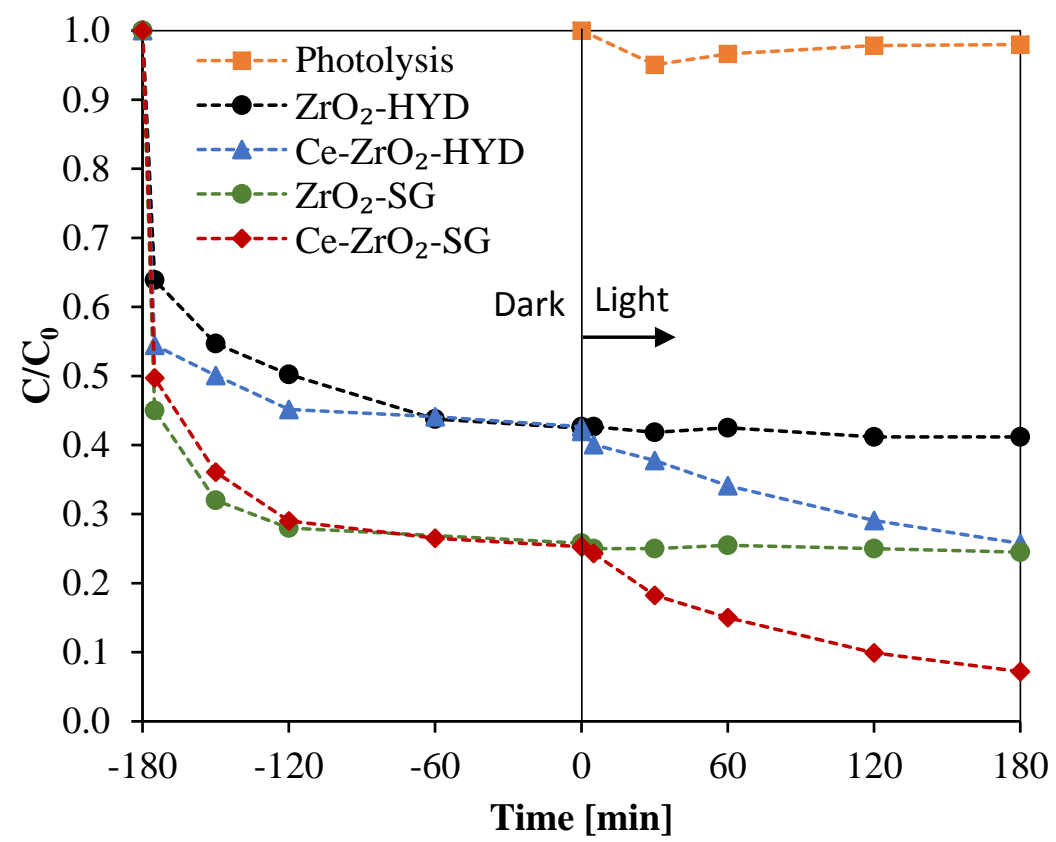

Figure 5. Adsorption and photodegradation of humic acid using different zirconia samples $\left([\mathrm{HA}]_{0}=\right.$ $10 \mathrm{mg} \cdot \mathrm{L}^{-1}, \mathrm{pH} 6.5$, catalyst dosage $=1 \mathrm{~g} \cdot \mathrm{L}^{-1}$ ).

From this figure, it can be observed that practically no degradation of the humic acid occurs under visible-light irradiation, in agreement with results reported by other authors $[35,55]$. It can also be noticed that in the presence of pure $\mathrm{ZrO}_{2}$, the removal of $\mathrm{HA}$ was caused only by adsorption. In fact, after reaching adsorption equilibrium, any further removal of HA under irradiation was not observed. This result corroborates the ones obtained by DRS and previous electron paramagnetic resonance (EPR) characterization $[27,33,34,42]$ since pure zirconia presents a wide band gap value of $5.2 \mathrm{eV}$, and visible-light irradiation is not able to promote the charge separation. Thus, without photo-induced electrons and hole, neither the direct oxidation of HA nor the generation of radicals capable of degrading HA are possible. On the other hand, both hydrothermal and sol-gel Ce-doped $\mathrm{ZrO}_{2}$ adsorb $\mathrm{HA}$ under dark and are also able to degrade humic acid under visible light irradiation in a photocatalytic process. As discussed in the previous section, the cerium doping introduces in the oxide an intra band gap state based on the Ce $4 \mathrm{f}$ levels. Therefore, using a double jump mechanism, $\mathrm{Ce}-\mathrm{ZrO}_{2}$ can absorb visible light frequencies, promoting charge separation. Then, the photo-induced electrons and holes initiate the HA oxidation reactions. For the $\mathrm{Ce}-\mathrm{ZrO}_{2}-\mathrm{SG}$ sample, $93 \%$ of the humic acid was removed after 180 min of adsorption in the dark followed by $180 \mathrm{~min}$ of light irradiation.

\subsubsection{Effect of the Initial HA Concentration}

Considering the potential application of the material, it is important to study the dependence of removal efficiency with the initial humic acid concentration $\left([H A]_{0}\right)$. Depending on the source of water (surface, ground), season, proximity to urban centers, the concentration of organic matter can vary considerably, from a few $\mathrm{mg} \cdot \mathrm{L}^{-1}$ to more than a hundred. Therefore, the values of initial HA concentration studied were those typically reported in works devoted to advanced oxidation process $[21,22,36]$. Figure 6 shows the photocatalytic experiment results starting from different initial 
HA concentrations using $1 \mathrm{mg} \cdot \mathrm{L}^{-1}$ of the hydrothermally and sol-gel prepared $\mathrm{Ce}-\mathrm{ZrO}_{2}$. It can be observed that HA removal decreases increasing the initial HA concentration, as also observed by other authors [35,36]. The explanation relies on the fact that at higher concentrations, more HA molecules are adsorbed at the zirconia nanoparticles surface, reducing the availability of the sites active for the photocatalytic reaction [36] and also increasing the repulsion for non-adsorbed HA molecules [56]. In addition, the adsorbed colored HA molecules may also hinder the absorption of light by the zirconia particles, slowing down the degradation rate. It is also possible that since the same dosage of catalyst was used and consequently the number of radicals generated was the same, a less concentrated HA solution can be degraded more efficiently in shorter time.
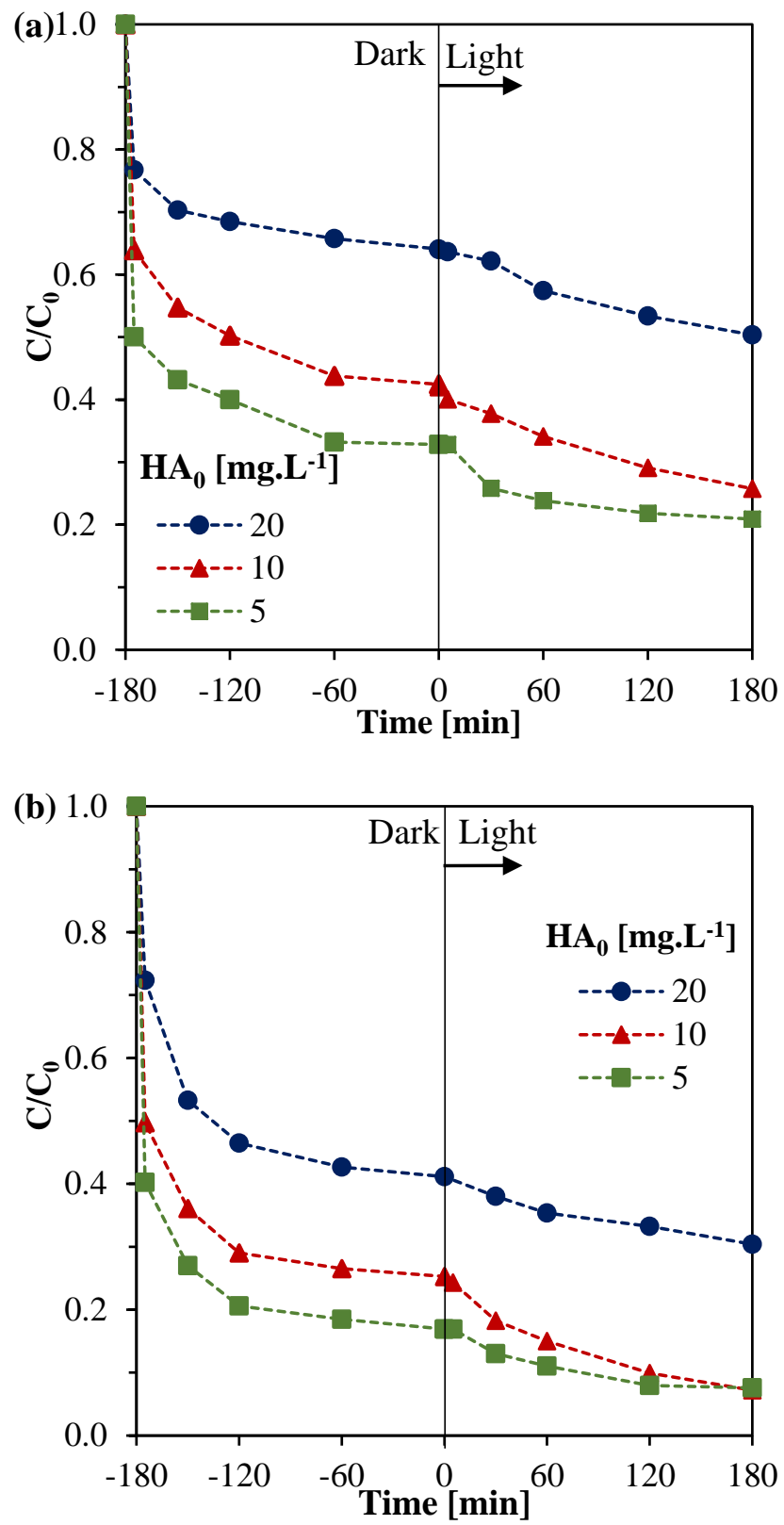

Figure 6. Effect of initial humic acid concentration on humic acid (HA) removal using (a) $\mathrm{Ce}-\mathrm{ZrO}_{2}-\mathrm{HYD}$ and $(\mathbf{b}) \mathrm{Ce}-\mathrm{ZrO}_{2}-\mathrm{SG}\left(\mathrm{pH} 6.5\right.$, catalyst dosage $\left.=1 \mathrm{~g} \cdot \mathrm{L}^{-1}\right)$.

The kinetic modelling helps to draw a conclusion about reaction rates and provides useful rate equations for engineering the development of the system. For photocatalytic reactions, especially in the ones where adsorption represents a critical step in the photo-oxidation processes, 
the Langmuir-Hinshelwood model is the most used [22,45,57-59]. This model assumes that both oxidant and reducer are rapidly adsorbed and the rate-determining step of the reaction involves these both species present in a monolayer at the solid-liquid interface [60]. The initial reaction rate, $r_{0}\left[\mathrm{mg} \cdot \mathrm{L}^{-1} \cdot \mathrm{min}^{-1}\right]$, in the Langmuir-Hinshelwood model can be expressed as follows:

$$
r_{0}=\frac{-d C}{d t}=k \frac{K_{a d s} C}{1+K_{a d s} C}=k_{o b s} C
$$

where $k$ is the apparent reaction rate constant $\left[\mathrm{mg} \cdot \mathrm{L}^{-1} \cdot \mathrm{min}^{-1}\right]$, and $K_{a d s}$ is the adsorption equilibrium constant [L·mg $\left.{ }^{-1}\right]$. These constants can be grouped in a lumped parameter to obtain a pseudo-first-order kinetic equation, in which $k_{o b s}\left[\mathrm{~min}^{-1}\right]$ is the pseudo-first-order rate constant. Upon integration and linearization of Equation (2), it is possible to determine $k_{\text {obs }}$ by fitting the experimental data (Figure S5). The values obtained are shown in Table 3. With these values, it is possible to calculate the Langmuir-Hinshelwood constants (Table 3) by another linear fit (Figure S6) using the linearized form of Equation (2), as follows:

$$
\frac{1}{k_{o b s}}=\frac{1}{k} C_{0}+\frac{1}{k K_{a d s}}
$$

Table 3. Pseudo-first-order kinetic rate constants $\left(K_{o b s}\right)$ in photocatalytic experiments with different

\begin{tabular}{|c|c|c|c|c|c|}
\hline Catalyst & $\begin{array}{c}{[\mathrm{HA}]_{0}} \\
{\left[\mathrm{mg} \cdot \mathrm{L}^{-1}\right]}\end{array}$ & $\left.\mathbf{k}_{\text {obs }} \min ^{-1}\right]$ & $r^{2}$ & {$\left[\begin{array}{c}\mathrm{k} \\
{\left[\mathrm{mg} \cdot \mathrm{L}^{-1} \cdot \mathrm{min}^{-1}\right]}\end{array}\right.$} & $\begin{array}{c}\mathrm{K}_{\mathrm{ads}} \\
{\left[\mathrm{L} \cdot \mathrm{mg}^{-1}\right]}\end{array}$ \\
\hline \multirow{3}{*}{$\mathrm{Ce}-\mathrm{ZrO}_{2}-\mathrm{HYD}$} & 20 & 0.0023 & 0.96 & \multirow{3}{*}{0.058} & \multirow{3}{*}{0.24} \\
\hline & 10 & 0.0049 & 0.97 & & \\
\hline & 5 & 0.0053 & 0.94 & & \\
\hline \multirow{3}{*}{$\mathrm{Ce}-\mathrm{ZrO}_{2}$-SG } & 20 & 0.0040 & 0.91 & \multirow{3}{*}{0.099} & \multirow{3}{*}{0.28} \\
\hline & 10 & 0.0097 & 0.96 & & \\
\hline & 5 & 0.0091 & 0.96 & & \\
\hline
\end{tabular}
initial HA concentrations $\left([H A]_{0}\right)$ and the Langmuir-Hinshelwood equation fitted parameters $\left(k, K_{a d s}\right)$.

Wang et al. [35] also applied the Langmuir-Hinshelwood modeling to the photodegradation of humic acid. The composite $\mathrm{ZnO}-\mathrm{TiO}_{2}$-Bamboo charcoal was used as a catalyst. These authors reported a value of $0.22 \mathrm{~L} \cdot \mathrm{mg}^{-1}$ for $K_{a d s}$, which is in agreement with the value obtained in the present work, and $0.87 \mathrm{mg} \cdot \mathrm{L}^{-1} \cdot \mathrm{min}^{-1}$ for the apparent reaction rate, $k$. Although this value is one order of magnitude higher than that obtained in our experiments, the measured irradiance applied by those authors was 1500 against $30 \mathrm{w} \cdot \mathrm{m}^{-2}$ in the present work, justifying the results.

Comparing hydrothermal and sol-gel prepared $\mathrm{Ce}-\mathrm{ZrO}_{2}$, the sol-gel sample exhibits higher rate constants (Table 3) and higher removal of humic acid combining adsorption and photodegradation (Figure 6). In addition, several membrane coating techniques are derived from sol-gel chemistry [61-64]; therefore, considering further application of doped zirconia as an anti-fouling layer in filtration membranes, the rest of the study will be focused on the sol-gel $\mathrm{Ce}-\mathrm{ZrO}_{2}$.

\subsubsection{Effect of the Initial $\mathrm{pH}$}

Solution $\mathrm{pH}$ is a relevant operational parameter since it governs the protonation/deprotonation of organic compounds and the surface functional groups of zirconia, thus, affecting the efficiency of adsorption and photocatalysis [65]. In addition, elevated costs can arise from $\mathrm{pH}$ adjustment, which can determine the feasibility of the processes. Therefore, to investigate the effect of the $\mathrm{pH}$ on the photocatalytic degradation efficiency of HA, the values of 5.0, 6.5, and 8.0 wer chosed to work at, which are not so far from neutrality and within the range of natural surface waters [66]. In the experiments, $1 \mathrm{~g} \cdot \mathrm{L}^{-1}$ of $\mathrm{Ce}-\mathrm{ZrO}_{2}-\mathrm{SG}$ was used and an initial $\mathrm{HA}$ concentration of $10 \mathrm{mg} \cdot \mathrm{L}^{-1}$; the results, as obtained 
with preliminary adsorption carried out in the dark (adsorption contribution) and with subsequent irradiation (adsorption + photocatalytic removal), are shown in Figure 7.

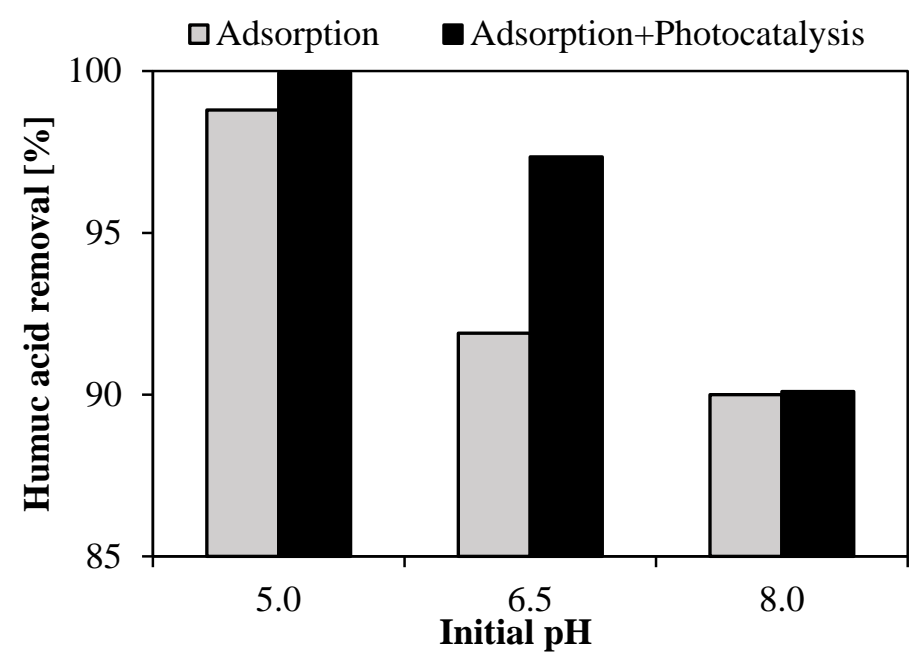

Figure 7. Effect of initial $\mathrm{pH}$ on humic acid removal using $1 \mathrm{~g} \cdot \mathrm{L}^{-1}$ of $\mathrm{Ce}-\mathrm{ZrO}_{2}-\mathrm{SG}$ catalyst $\left([\mathrm{HA}]_{0}=\right.$ $\left.10 \mathrm{mg} \cdot \mathrm{L}^{-1}\right)$.

An increasing trend in HA removal as the acidity increases can be observed, in agreement with other works on photocatalytic degradation of HA $[35,36,58]$. However, it should be noted that HA adsorption at the catalyst surface, which is an important step in the photodegradation process [58], was also higher at lower $\mathrm{pH}$ values. As discussed before, the HA adsorption is intensely affected by the solution $\mathrm{pH}$, since in the acid $\mathrm{pH}$ range, the solubility of HA decreases considerably while its negative charge decreases. At the same time, the surface charge of zirconia becomes less negative, favoring the HA adsorption. Regarding the photocatalytic activity, for $\mathrm{TiO}_{2}$ based photocatalysts, it has been reported that, under acidic conditions, the catalyst surface is more conducive for electrons leading to production of a photocurrent [67], which contributes to the generation of reactive oxygen species, and meanwhile avoids the recombination of electrons and holes [58]. Therefore, since adsorption is the dominant mechanism in the HA removal [21], the larger difference between adsorption and adsorption + photocatalysis was obtained at $\mathrm{pH} 6.5$, which was used in further experiments.

\subsubsection{Effect of Catalyst Dosage}

The influence of the amount of $\mathrm{Ce}-\mathrm{ZrO}_{2}-\mathrm{SG}$ nanopowder on the photodegradation efficiency is shown in Figure 8. The increase of the catalyst dosage leads to an increase of HA removal by both adsorption and photocatalytic mechanisms. Higher doses of catalyst imply higher surface area and number of active sites available, which favors light interaction and HA adsorption [68]. On the other side, it has been reported in some studies, that higher doses of catalyst could lead to negative effects due to light scattering and agglomeration of nanoparticles [36,68-72]. However, at least apparently, these phenomena were not observed in the catalyst dosage range tested, as the trend of adsorption contribution and adsorption + photocatalytic removal remains the same. 


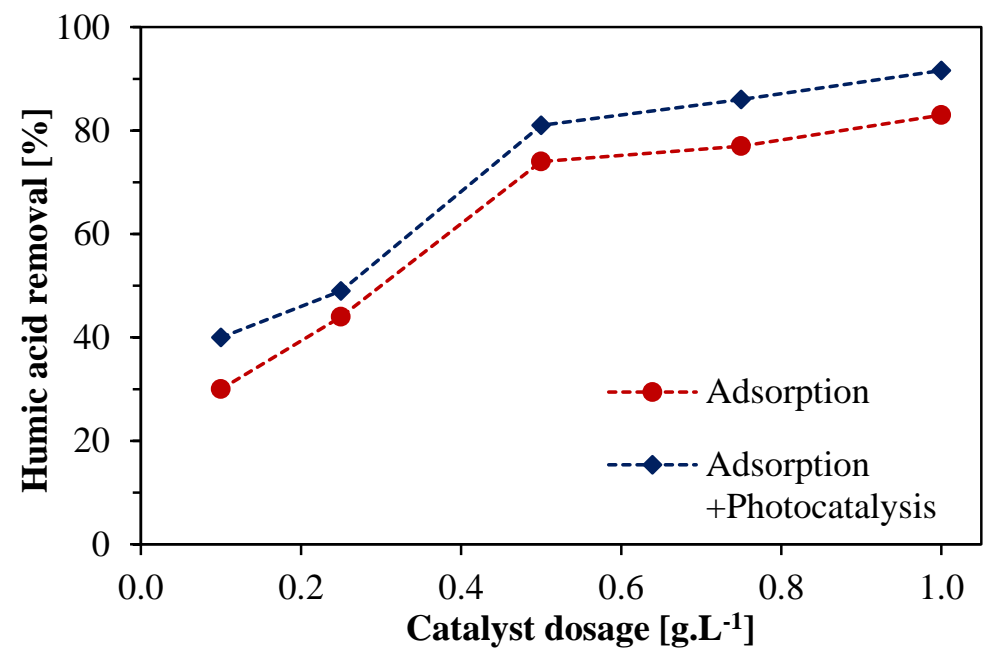

Figure 8. Effect of $\mathrm{Ce}-\mathrm{ZrO}_{2}-\mathrm{SG}$ catalyst dosage on humic acid removal $\left(\mathrm{pH} 6.5,[\mathrm{HA}]_{0}=10 \mathrm{mg} \cdot \mathrm{L}^{-1}\right)$.

\subsection{Stability of $\mathrm{Ce}-\mathrm{ZrO}_{2}$ Photocatalyst}

The stability of photocatalyst and its auto-regeneration capacity is critical for its application in controlling fouling in membrane filtration processes. To demonstrate the potential applicability of $\mathrm{Ce}-\mathrm{ZrO}_{2}$ photocatalysts, the stability of $\mathrm{Ce}-\mathrm{ZrO}_{2}-\mathrm{SG}$ nanoparticles was investigated. Figure 9 shows the results of HA removal in multiple degradation cycles. It can be observed that there is a loss of performance from the first to the second cycle, but the performance keeps relatively stable from the second to the following two photodegradation cycles. It can be presumed that some HA molecules of high molecular weight and aromaticity are not completely degraded, accumulating in the solution. In addition, unreacted HA molecules, adsorbed on zirconia nanoparticles, can block $\mathrm{ZrO}_{2}$ active sites and the light absorption. It is worth noting that no treatment, such as washing, was performed between the cycles. At the end of a cycle, a concentrated HA solution was added to achieve the initial HA concentration, and the dispersion was irradiated again for $180 \mathrm{~min}$. Therefore, these results suggest that Ce-doped zirconia have relatively stable performance as the active sites are regenerated under irradiation.

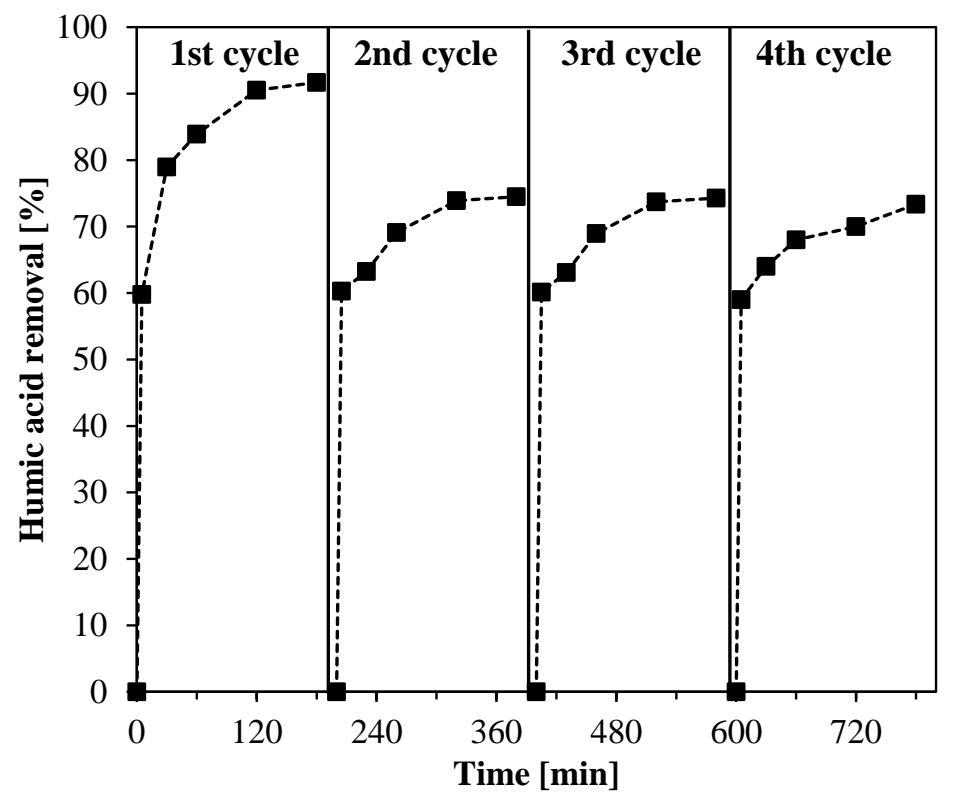

Figure 9. Removal of humic acid in multiple photodegradation tests $\left(\mathrm{Ce}-\mathrm{ZrO}_{2}-\mathrm{SG}\right.$ dosage $=1 \mathrm{~g} \cdot \mathrm{L}^{-1}$, $\left.\mathrm{pH}=6.5,[\mathrm{HA}]_{0}=10 \mathrm{mg} \cdot \mathrm{L}^{-1}\right)$. 


\subsection{Spectral and TOC Changes in Treated HA Solutions}

In Figure 10a, the removal of humic acid, using $\mathrm{Ce}-\mathrm{ZrO}_{2}$ in the dark (adsorption) and under visible light irradiation (Ads+Photocatalysts), is presented in terms of TOC and UV absorption at $254 \mathrm{~nm}\left(\mathrm{UV}_{254}\right)$. It is worth noting that both $\mathrm{UV}_{254}$ absorbance and TOC values are used to quantify the humic acid, but a mathematical correlation of these two values is required to compare their absolute values directly [66]. In addition, the TOC measurements can be considered as preliminary analysis, given the complexity of quantifying the HA by this technique. The determination of a calibration curve and more replicates would be needed to provide more accurate results. Nevertheless, UV-Vis analyses were performed in triplicates and presented with the respective error bars.
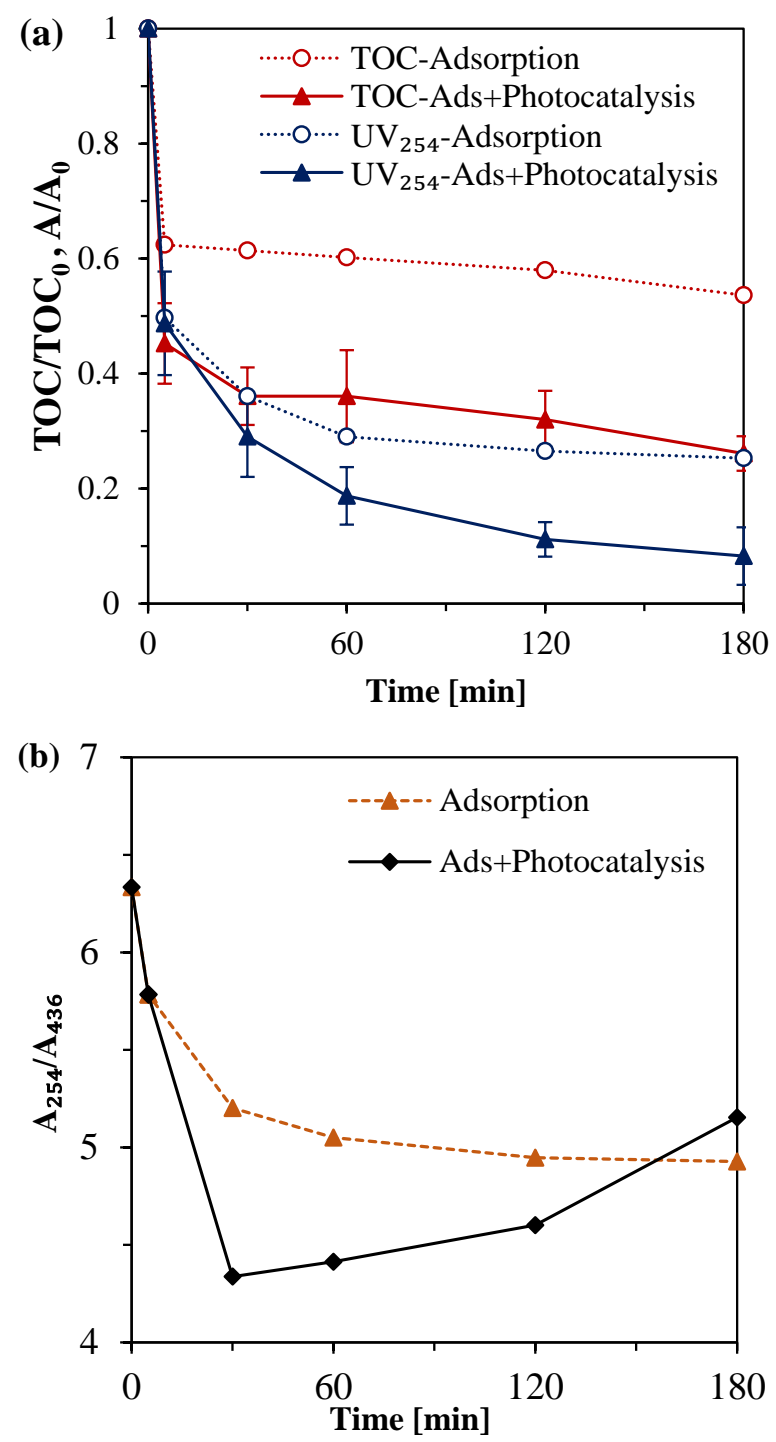

Figure 10. (a) Removal of humic acid in terms of total organic carbon (TOC) and UV $254 \mathrm{~nm}$ absorbance; (b) ratio between UV-Vis absorbance values at the wavelength of 254 and $436 \mathrm{~nm}\left(\mathrm{~A}_{254} / \mathrm{A}_{436}\right)$ in HA photodegradation tests $\left(\mathrm{Ce}-\mathrm{ZrO}_{2}-\mathrm{SG}\right.$ dosage $\left.=1 \mathrm{~g} \cdot \mathrm{L}^{-1}, \mathrm{pH}=6.5,[\mathrm{HA}]_{0}=10 \mathrm{mg} \cdot \mathrm{L}^{-1}\right)$.

From Figure 10a, it can be observed that the TOC reduction is lower than the $\mathrm{UV}_{254}$ absorbance reduction, indicating that the HA is probably degraded to intermediates, such as alcohols, aldehydes, ketones, and carboxylic acids [40], higher UV radiation absorbing compounds. Nevertheless, comparing the final TOC values, there is a considerable difference in the values of adsorption and photocatalysis, which is evidence that some degree of mineralization was achieved. These results are 
in agreement with $\mathrm{HA}$ degradation employing as photocatalysts $\mathrm{TiO}_{2} / \mathrm{Fe}_{2} \mathrm{O}_{3} / \mathrm{GO}$ [21], $\mathrm{TiO}_{2} / \mathrm{ZnO}$ [35], and $\mathrm{ZnO}$ [36].

Uyguner and Bekbolet [40], studying the different molecular weights fraction of humic acid after a $\mathrm{TiO}_{2}$ photocatalytic treatment, verified that the ratio between the absorption in wavelengths 254 and $436 \mathrm{~nm}\left(\mathrm{~A}_{254} / \mathrm{A}_{436}\right)$ could be used as an indicative parameter of photocatalytic degradation: an increase of the ratio was associated with a reduction in the higher molecular weight fractions of humic acid, which have higher aromaticity than the lighter fraction. Therefore, this ratio $\mathrm{A}_{254} / \mathrm{A}_{436}$ was calculated for the HA photocatalytic degradation with $\mathrm{Ce}-\mathrm{ZrO}_{2}$ and presented in Figure $10 \mathrm{~b}$.

It can be observed that the ratio $\mathrm{A}_{254} / \mathrm{A}_{436}$ presents a fast decrease at the beginning of the experiment in the dark, and then it stabilizes because adsorption equilibrium was reached. This indicates that the HA molecules of lower molecular weight are preferentially adsorbed at the zirconia surface, since higher molecular weight fractions have higher aromaticity [40] and, thus, a more limited interaction with zirconia. Under irradiation, the ratio $\mathrm{A}_{254} / \mathrm{A}_{436}$ first decreases due to $\mathrm{HA}$ adsorption and then it increases continuously, since HA molecules have been degraded to lower molecular weight compounds.

\subsection{Effect of Scavengers-Photocatalytic Mechanism}

Among the mechanisms proposed for the degradation of organic molecules in photocatalytic processes, two of them have been frequently reported $[45,73,74]$. In the direct oxidation mechanism, the photo-induced holes oxidize the organic molecule adsorbed on the catalyst. In the indirect mechanism, photo-induced holes and electrons generate reactive oxygen species (ROS), mainly ${ }^{\bullet} \mathrm{OH}$ radicals, that degrade the adsorbed organic molecule $[45,55,73]$. In both cases, adsorption of the organic molecule is critical in the photocatalytic degradation, since photocatalytic reactions proceed at the surface or near the semiconductor surface [45]. In dye bleaching studies, a third mechanism is also reported, in which the dye acts as a photosensitizer by adsorbing the light and generating or initiating the reactions of ROS formation [75]. However, this mechanism does not seem probable for the humic acid photodegradation under visible light, considering that HA solutions do not have higher absorption in the visible region. As discussed in previous works [27,33,34,42], EPR studies indicated the generation of photo-induced holes and electrons, and the formation of ${ }^{\bullet} \mathrm{OH}$ radicals when Ce-doped $\mathrm{ZrO}_{2}$ was irradiated. Hence, to elucidate HA degradation mechanism with doped zirconia, a series of experiments were performed with disodium ethylenediaminetetraacetate ( $\mathrm{Na}_{2}$-EDTA) (pointed as scavenger for holes [76] and a chelating agent that prevents HA adsorption on the oxide surface $[73,77]$ ) and isopropanol (commonly used as scavenger of ${ }^{\bullet} \mathrm{OH}$ radical $\left.[77,78]\right)$. The results are shown in Figure 11.

In the presence of $\mathrm{Na}_{2}$-EDTA, it can be observed that the photocatalytic degradation of humic acid is highly decreased since HA molecules are unable to adsorb at the zirconia surface to undergo the oxidation reactions. Exhibiting a concentration-dependent effect, isopropanol also reduces the HA photodegradation efficacy by quenching ${ }^{\bullet} \mathrm{OH}$ radicals. Thus, it can be inferred that ${ }^{\bullet} \mathrm{OH}$ radicals are also responsible for the HA oxidation.

Finally, considering previous EPR results [33] and the present observations in the HA degradation a mechanism for the humic acid degradation under visible light irradiation using with $\mathrm{Ce}-\mathrm{ZrO}{ }_{2}$ as a photocatalyst is proposed in Scheme 1. First, in a double jump mechanism, Ce-doped $\mathrm{ZrO}_{2}$ adsorbs visible light photons promoting the photo-induced charge separation. Then, the zirconia valence band trapped holes $\left(\mathrm{h}^{+}{ }_{(\mathrm{VB})}\right)$ : (a) directly extracting electrons from the adsorbed HA molecules and oxidizing them; and/or (b) reacting with the ${ }^{-} \mathrm{OH}$ groups adsorbed on the photocatalyst $\left({ }^{-} \mathrm{OH}_{(\mathrm{ads})}\right)$ producing adsorbed ${ }^{\bullet} \mathrm{OH}$ radicals $\left({ }^{\bullet} \mathrm{OH}(\right.$ ads) $)$ which successively oxidize HA molecules at the catalyst surface. Finally, in a less likely process, (c) the generated ${ }^{\bullet} \mathrm{OH}$ radicals are released from the surface to the solution and oxidize HA molecules distant from the photocatalyst surface. Although this possibility was not evaluated in the tests with scavengers, (d) the superoxide anion radical $\left({ }^{\bullet} \mathrm{O}_{2}^{-}\right)$, generated by photo-induced electrons $\left(\mathrm{e}^{-}(\mathrm{CB})\right)$, could also degrade the HA. 


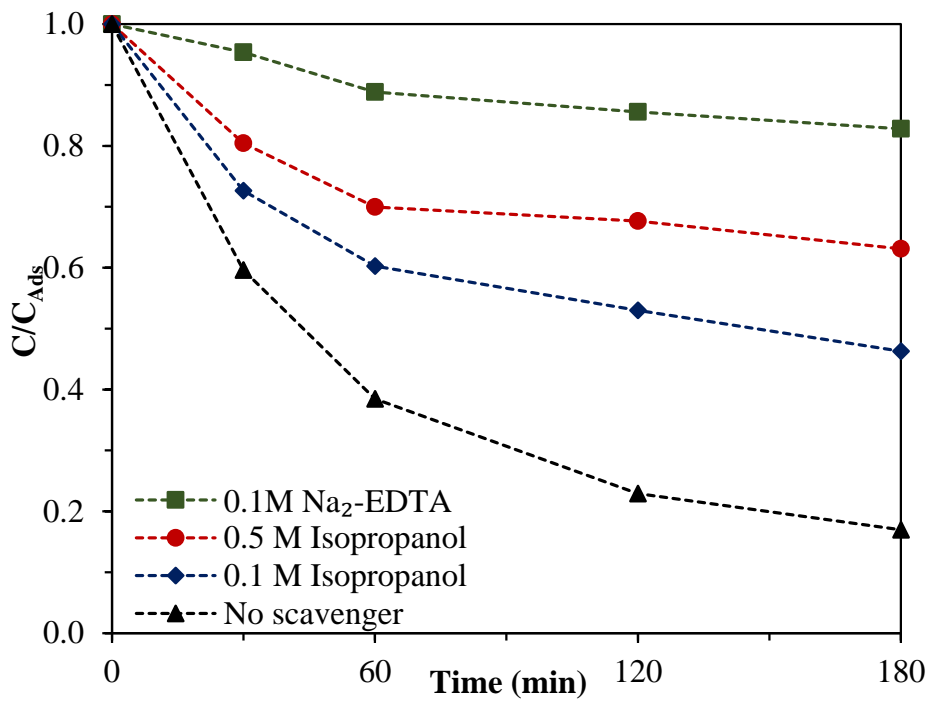

Figure 11. Removal of HA in photocatalytic treatments with and without scavengers. The curves were calculated considering as initial concentration, $\mathrm{C}_{\mathrm{Ads}}$, the $\mathrm{HA}$ concentration after adsorption equilibrium $\left(\mathrm{Ce}-\mathrm{ZrO}_{2}-\mathrm{SG}\right.$ dosage $\left.=1 \mathrm{~g} \cdot \mathrm{L}^{-1}, \mathrm{pH}=6.5,[\mathrm{HA}]_{0}=10 \mathrm{mg} \cdot \mathrm{L}^{-1}\right)$.
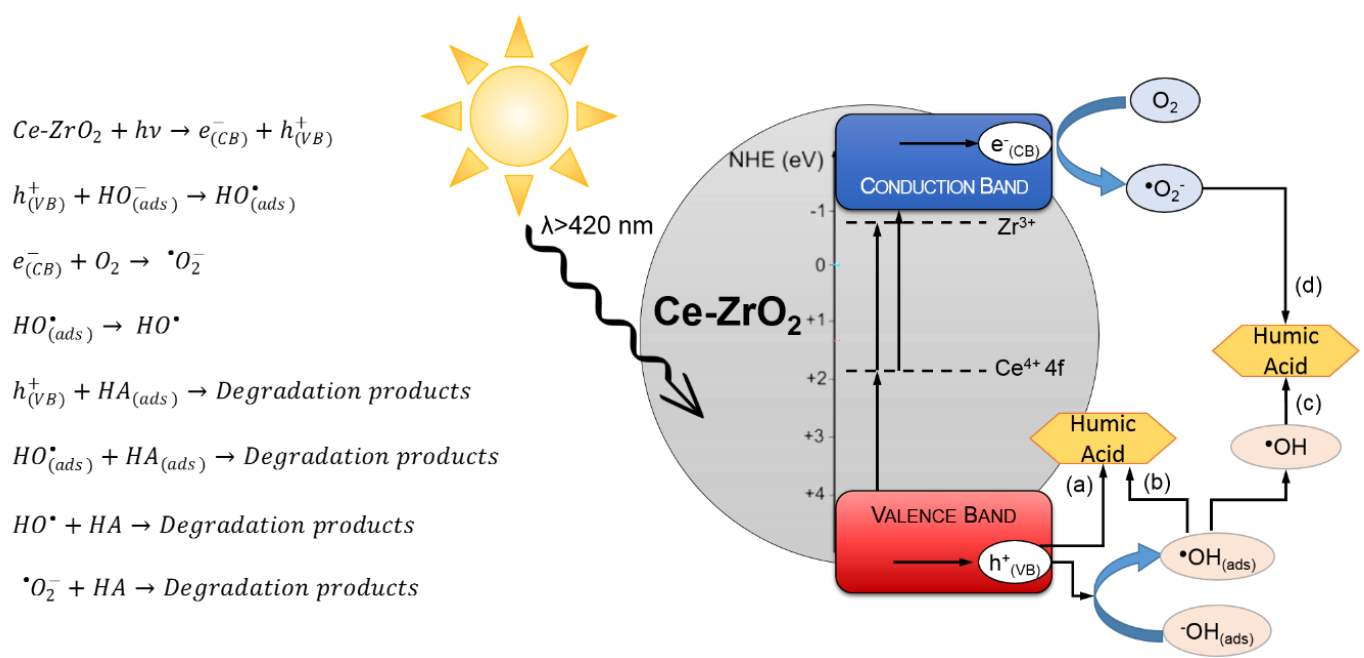

Scheme 1. Proposed mechanism for the photodegradation of humic acid (HA) under visible light using $\mathrm{Ce}-\mathrm{ZrO}_{2}$ as photocatalyst.

\subsection{Filtration Experiments with the Photocatalytic Membranes}

Initially, the flux of pure water in the photocatalytic membrane was measured. A value of $95.2 \mathrm{~L} \cdot \mathrm{h}^{-1} \cdot \mathrm{m}^{-2}$ was obtained for the filtration under dark, and this was considered the initial flux $\mathrm{J}_{0}$ for further experiments. In the filtration of a humic acid solution $\left(15 \mathrm{mg} \cdot \mathrm{L}^{-1}\right)$, under dark conditions, the permeate flux decreased almost $90 \%$, from 60 to $6.3 \mathrm{~L} \cdot \mathrm{h}^{-1} \cdot \mathrm{m}^{-2}$, in less than one hour (Figure 12a). This rapid and extensive reduction in the flux can be attributed to irreversible fouling caused by the chemical adsorption of humic acid into the membrane surface [6] since humic acid has a strong affinity with the polar groups [10] present in both $\mathrm{ZrO}_{2}$ particles and filter paper. The fouling of the membrane was also visually observed by comparing the membrane before and after the HA filtration, as shown in Figure 13. This figure also shows the membrane after filtration under irradiation, in which a change in the color was observed, but it remained colored since the feed solution still had $14 \mathrm{mg} \cdot \mathrm{L}^{-1}$ of humic acid. 

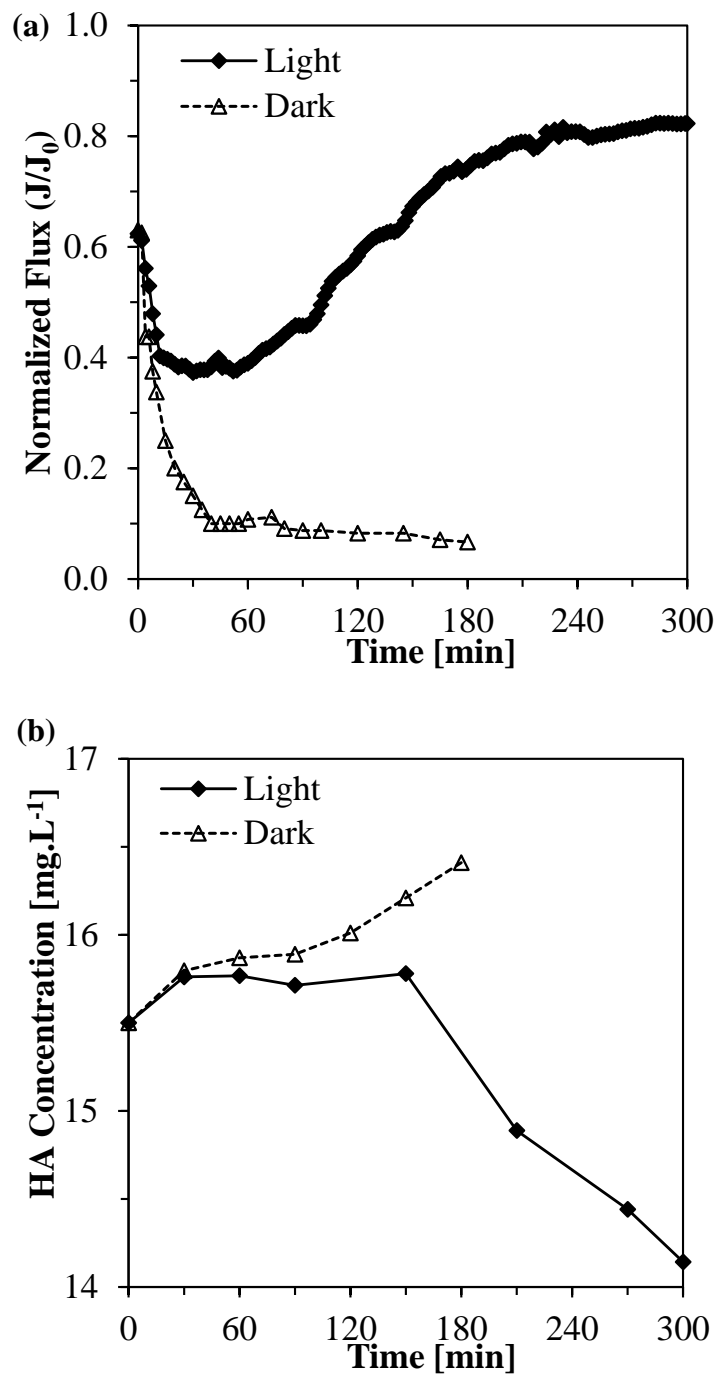

Figure 12. (a) Normalized permeate flux and (b) HA concentration in the feed stream for HA filtration tests in the dark and under visible light irradiation. $\left(\mathrm{J}_{0}=\right.$ pure water flux $\left.=95.2 \mathrm{~L} \cdot \mathrm{h}^{-1} \cdot \mathrm{m}^{-2}\right)$.

The HA retention was around $60 \%$ for the experiments in the dark and under irradiation. Therefore, as the feed was recirculated, the concentration of HA in the feed tends to increase during the filtration, as observed in the dark filtration test (Figure 12b).

In the filtration experiment with visible light irradiation (Figure 12a), the flux initially decreased due to the HA adsorption in the membrane; however, after one hour, the flux started to increase, recovering the initial value after another hour. Then, the further increase in the flux may be explained by the degradation of the humic acid in the feed solution. Although it was not evaluated, there is the possibility that under irradiation, the hydrophilicity and wettability of the zirconia surface increases favoring the water flux, which has been reported for $\mathrm{TiO}_{2}$ under UV-light irradiation [1].

From Figure 12b, it can be observed that, in the experiment with light, the HA concentration did not increase as in the dark experiment, but it even decreased. This indicates that the $\mathrm{Ce}-\mathrm{ZrO}_{2}$ nanoparticles were able not only to reduce the fouling but also to photodegrade the humic acid.

To evaluate the possibility of using the light to clean the fouled photocatalytic membranes, initially the filtration was performed in the dark; and then, irradiation was started. In the dark, the permeate flux reduced $80 \%$, as shown in Figure 14a, due to the HA fouling. Measuring the permeate volume and its HA concentration it was possible, through a mass balance, to estimate the HA concentration in the feed under dark conditions (dashed line in Figure 14b), which exhibits an increasing trend. The experimental HA concentration values matched this increasing trend but, after starting light 
irradiation, the HA concentration declined and the permeate flux started to increase (Figure 14). After $4 \mathrm{~h}$ of irradiation, the flux was the double the value after fouling. Therefore, it can be said that the light was able to degrade part of the HA that was fouled in the photocatalytic membrane, promoting the recovery of the flux, and to degrade the HA in the feed stream.
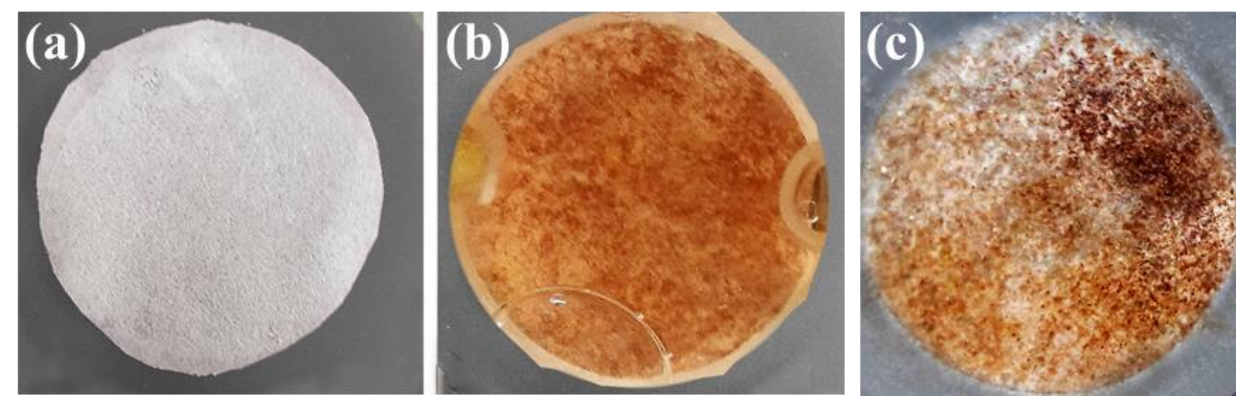

Figure 13. Photocatalytic membranes prepared with $\mathrm{Ce}-\mathrm{ZrO}_{2}-\mathrm{SG}$ : (a) before filtration, (b) after HA filtration in the dark, and (c) after filtration under irradiation.
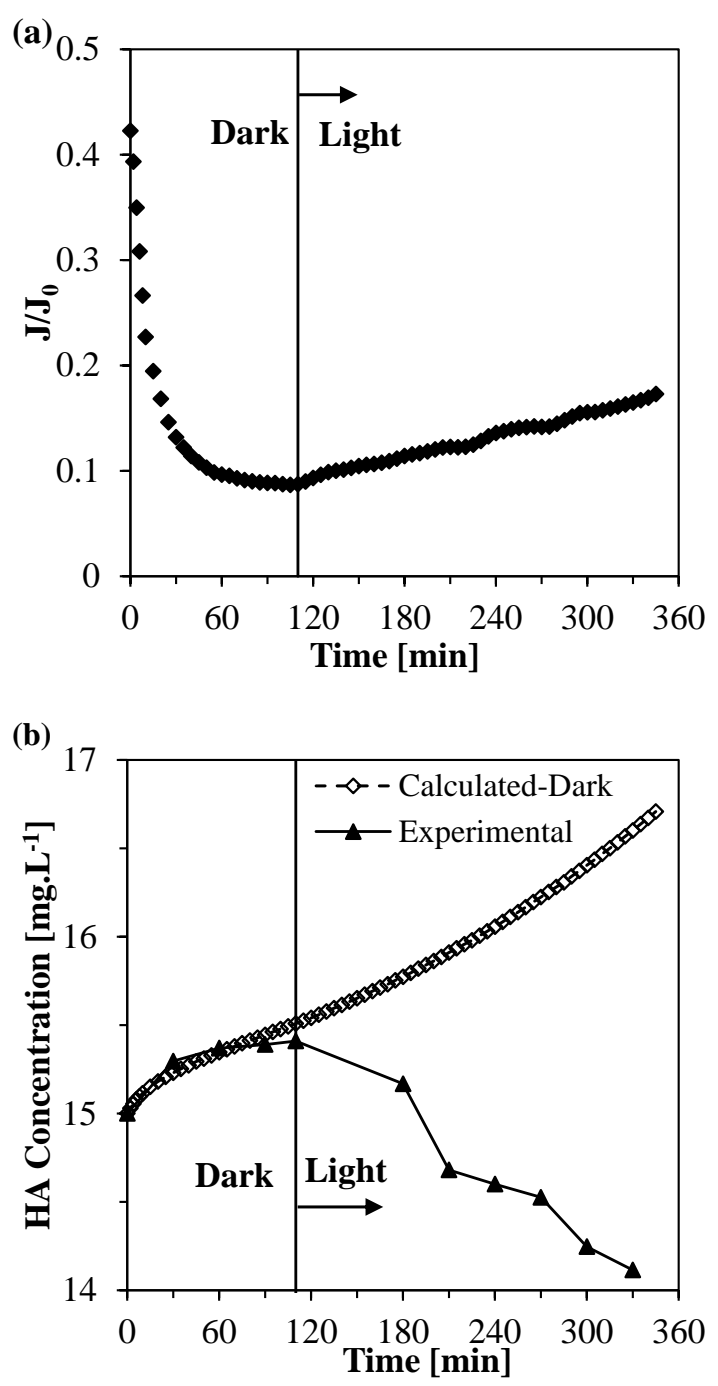

Figure 14. (a) Normalized permeate flux and (b) HA concentration in the feed stream for HA filtration test initially in the dark and after starting visible light irradiation. $\left(\mathrm{J}_{0}=\right.$ pure water flux $\left.=95.2 \mathrm{~L} \cdot \mathrm{h}^{-1} \cdot \mathrm{m}^{-2}\right)$. 


\section{Conclusions}

Ce-doped $\mathrm{ZrO}_{2}$ nanoparticles with photocatalytic activity under visible light were synthesized in this study by hydrothermal and sol-gel processes. The addition of a small amount of cerium introduces intra band gap states that act as a bridge between the VB and the CB of zirconia, allowing the absorption of low-energy photons in a double jump mechanism $[33,34]$. Therefore, a red shift in the absorption spectra is observed, indicating the possibility to use visible light to promote charge separation and the generation of ROS to degrade organic compounds. Thus, this catalyst can be considered a third-generation photocatalyst [79]. Ce- $\mathrm{ZrO}_{2}$ was then applied in the photodegradation of humic acid, a good model molecule for membrane fouling tests. As a result, it was observed that the photocatalytic process led to the degradation of HA into smaller molecules, as indicated by spectroscopic and TOC changes. Sol-gel prepared $\mathrm{Ce}-\mathrm{ZrO}_{2}$ exhibited higher HA removal, achieving 93\% of efficiency in 180 min of irradiation using RGB LEDs as light source, after 180 min of adsorption in the dark. Further experiments also confirmed the catalyst activity in neutral $\mathrm{pH}$ conditions and its stability for several photocatalytic cycles. Finally, zirconia nanoparticles were applied in the fabrication of photocatalytic membranes, in which it was possible to improve anti-fouling resistance by degrading HA in filtration tests under visible light irradiation. In addition, it was possible to clean a fouled membrane promoting the recovery of the flux. The present findings point to the further development of $\mathrm{Ce}-\mathrm{ZrO}_{2}$ photocatalytic membranes with improved anti-fouling properties. This will be important for new industrial applications of membrane filtration processes, especially for water treatment. In such processes, solar light photocatalysis can be used to degrade organic fouling compounds and possibly contaminants of emerging concern, which would have remarkable environmental implications. Therefore, this system requires more studies for its optimization and testing with real water samples.

Supplementary Materials: The following are available online at http:/ /www.mdpi.com/2079-4991/9/4/534/s1, Figure S1: XRD patterns of pure and Ce-doped $\mathrm{ZrO}_{2}$ prepared by hydrothermal and sol-gel processes. Triangles and squares on top of the patterns indicate the peaks of monoclinic $\left(\mathrm{m}-\mathrm{ZrO}_{2}, \mathrm{ICSD} \# 658755\right)$ and tetragonal $\left(\mathrm{t}-\mathrm{ZrO}_{2}, \mathrm{ICSD} \# 66781\right)$ phases, respectively, Figure S2: FTIR spectra of $\mathrm{Ce}-\mathrm{ZrO}_{2}$ samples prepared by hydrothermal (HYD) and sol-gel (SG) processes. FTIR spectra were registered in transmission mode using a Bruker Vector 22 spectrophotometer equipped with Globar source, DTGS detector, and working with 128 scans at $4 \mathrm{~cm}^{-1}$ resolution in the $4000-400 \mathrm{~cm}^{-1}$ range. Samples were analyzed as self-supporting pellets by dispersing the samples in $\mathrm{KBr}$ (1:20 weight ratio), Figure S3: (a) UV-Vis-DRS spectra of pure and Ce-doped $\mathrm{ZrO}_{2}$ prepared by hydrothermal and sol-gel processes, (b) magnification of region 200-500 nm, Figure S4: Linear fitting of Langmuir isotherm equation to experimental data of $\mathrm{HA}$ absorption on $\mathrm{Ce}-\mathrm{ZrO}_{2}$ samples prepared by hydrothermal (HYD) and sol-gel (SG) processes, Figure S5: Determination of the pseudo-fist-order kinetic rate constants, $\mathrm{K}_{\mathrm{obs}}$, for (a) $\mathrm{Ce}-\mathrm{ZrO}_{2}-\mathrm{HYD}$ and (b) $\mathrm{Ce}-\mathrm{ZrO}_{2}-\mathrm{SG}$, Figure S6: Determination of the Langmuir-Hinshelwood model parameters for $\mathrm{Ce}-\mathrm{ZrO} \mathrm{O}_{2}$ samples prepared by hydrothermal (HYD) and sol-gel (SG) processes.

Author Contributions: Conceptualization, F.E.B.C., C.G., M.C.P., P.C. and G.M.; Formal analysis, C.G. and G.M.; Funding acquisition, P.C. and G.M.; Investigation, F.E.B.C., M.C.P. and G.M.; Methodology, F.E.B.C., C.G., M.C.P. and G.M.; Project administration, P.C. and G.M.; Supervision, M.C.P. and G.M.; Writing-original draft, F.E.B.C.; Writing-review and editing, F.E.B.C., C.G., M.C.P., P.C. and G.M.

Funding: This project has received funding from the European Union's Horizon 2020 research and innovation programme under the Marie Skłodowska-Curie grant agreement No 765860.

Acknowledgments: This project has received funding from the European Union's Horizon 2020 research and innovation programme under the Marie Skłodowska-Curie grant agreement No 765860.

Conflicts of Interest: The authors declare no conflict of interest.

\section{References}

1. Mendret, J.; Hatat-Fraile, M.; Rivallin, M.; Brosillon, S. Hydrophilic composite membranes for simultaneous separation and photocatalytic degradation of organic pollutants. Sep. Purif. Technol. 2013, 111, 9-19. [CrossRef]

2. Choi, H.G.; Son, M.; Yoon, S.H.; Celik, E.; Kang, S.; Park, H.; Park, C.H.; Choi, H. Alginate fouling reduction of functionalized carbon nanotube blended cellulose acetate membrane in forward osmosis. Chemosphere 2015, 136, 204-210. [CrossRef] 
3. Kim, D.H.; Lee, B.H. Pilot Study Analysis of Three Different Processes in Drinking Water Treatment. Environ. Eng. Res. 2011, 16, 237-242. [CrossRef]

4. Duong, H.C.; Duke, M.; Gray, S.; Cooper, P.; Nghiem, L.D. Membrane scaling and prevention techniques during seawater desalination by air gap membrane distillation. Desalination 2016, 397, 92-100. [CrossRef]

5. Mohammad, A.W.; Teow, Y.H.; Ang, W.L.; Chung, Y.T.; Oatley-Radcliffe, D.L.; Hilal, N. Nanofiltration membranes review: Recent advances and future prospects. Desalination 2015, 356, 226-254. [CrossRef]

6. Yuan, W.; Zydney, A.L. Humic Acid Fouling during Ultrafiltration. Environ. Sci. Technol. 2000, 34, 5043-5050. [CrossRef]

7. Charfi, A.; Jang, H.; Kim, J. Membrane fouling by sodium alginate in high salinity conditions to simulate biofouling during seawater desalination. Bioresour. Technol. 2017, 240, 106-114. [CrossRef] [PubMed]

8. Li, X.; Cao, Y.; Yu, H.; Kang, G.; Jie, X.; Liu, Z.; Yuan, Q. A novel composite nanofiltration membrane prepared with PHGH and TMC by interfacial polymerization. J. Memb. Sci. 2014, 466, 82-91. [CrossRef]

9. Wang, J.; Wang, Z.; Liu, Y.; Wang, J.; Wang, S. Surface modification of NF membrane with zwitterionic polymer to improve anti-biofouling property. J. Memb. Sci. 2016, 514, 407-417. [CrossRef]

10. Mustafa, G.; Wyns, K.; Vandezande, P.; Buekenhoudt, A.; Meynen, V. Novel grafting method efficiently decreases irreversible fouling of ceramic nanofiltration membranes. J. Memb. Sci. 2014, 470, 369-377. [CrossRef]

11. Goosen, M.F.A.; Sablani, S.S.; Al-Hinai, H.; Al-Obeidani, S.; Al-Belushi, R.; Jackson, D. Fouling of Reverse Osmosis and Ultrafiltration Membranes: A Critical Review. Sep. Sci. Technol. 2005, 39, 2261-2297. [CrossRef]

12. de Lara, R.; Benavente, J. Use of hydrodynamic and electrical measurements to determine protein fouling mechanisms for microfiltration membranes with different structures and materials. Sep. Purif. Technol. 2009, 66, 517-524. [CrossRef]

13. Hofs, B.; Ogier, J.; Vries, D.; Beerendonk, E.F.; Cornelissen, E.R. Comparison of ceramic and polymeric membrane permeability and fouling using surface water. Sep. Purif. Technol. 2011, 79, 365-374. [CrossRef]

14. Sun, X.; Wu, J.; Chen, Z.; Su, X.; Hinds, B.J. Fouling Characteristics and Electrochemical Recovery of Carbon Nanotube Membranes. Adv. Funct. Mater. 2013, 23, 1500-1506. [CrossRef]

15. Van der Bruggen, B.; Mänttäri, M.; Nyström, M. Drawbacks of applying nanofiltration and how to avoid them: A review. Sep. Purif. Technol. 2008, 63, 251-263. [CrossRef]

16. Kim, E.S.; Yu, Q.; Deng, B. Plasma surface modification of nanofiltration (NF) thin-film composite (TFC) membranes to improve anti organic fouling. Appl. Surf. Sci. 2011, 257, 9863-9871. [CrossRef]

17. Asatekin, A.; Kang, S.; Elimelech, M.; Mayes, A.M. Anti-fouling ultrafiltration membranes containing polyacrylonitrile-graft-poly(ethylene oxide) comb copolymer additives. J. Memb. Sci. 2007, 298, 136-146. [CrossRef]

18. Baek, Y.; Kim, C.; Seo, D.K.; Kim, T.; Lee, J.S.; Kim, Y.H.; Ahn, K.H.; Bae, S.S.; Lee, S.C.; Lim, J.; et al. High performance and antifouling vertically aligned carbon nanotube membrane for water purification. J. Memb. Sci. 2014, 460, 171-177. [CrossRef]

19. Tiraferri, A.; Kang, Y.; Giannelis, E.P.; Elimelech, M. Superhydrophilic Thin-Film Composite Forward Osmosis Membranes for Organic Fouling Control: Fouling Behavior and Antifouling Mechanisms. Environ. Sci. Technol. 2012, 46, 11135-11144. [CrossRef] [PubMed]

20. Feng, Y.; Wang, K.; Davies, C.; Wang, H. Carbon Nanotube/Alumina/Polyethersulfone Hybrid Hollow Fiber Membranes with Enhanced Mechanical and Anti-Fouling Properties. Nanomaterials 2015, 5, 1366-1378. [CrossRef]

21. Rao, G.; Zhang, Q.; Zhao, H.; Chen, J.; Li, Y. Novel titanium dioxide/iron (III) oxide/graphene oxide photocatalytic membrane for enhanced humic acid removal from water. Chem. Eng. J. 2016, 302, 633-640. [CrossRef]

22. Friedmann, D.; Mendive, $\mathrm{C}$.; Bahnemann, $\mathrm{D}$. $\mathrm{TiO}_{2}$ for water treatment: Parameters affecting the kinetics and mechanisms of photocatalysis. Appl. Catal. B Environ. 2010, 99, 398-406. [CrossRef]

23. Takeuchi, M.; Yamashita, H.; Matsuoka, M.; Anpo, M.; Hirao, T.; Itoh, N.; Iwamoto, N. Photocatalytic decomposition of $\mathrm{NO}$ under visible light irradiation on the $\mathrm{Cr}$-ion-implanted $\mathrm{TiO}_{2}$ thin film photocatalyst. Catal. Lett. 2000, 67, 135-137. [CrossRef]

24. Asahi, R. Visible-Light Photocatalysis in Nitrogen-Doped Titanium Oxides. Science 2001, 293, $269-271$. [CrossRef]

25. Warren, S.C.; Thimsen, E. Plasmonic solar water splitting. Energy Environ. Sci. 2012, 5, 5133-5146. [CrossRef] 
26. Maeda, K.; Domen, K. Photocatalytic Water Splitting: Recent Progress and Future Challenges. J. Phys. Chem. Lett. 2010, 1, 2655-2661. [CrossRef]

27. Gionco, C.; Paganini, M.C.; Giamello, E.; Sacco, O.; Vaiano, V.; Sannino, D. Rare earth oxides in zirconium dioxide: How to turn a wide band gap metal oxide into a visible light active photocatalyst. J. Energy Chem. 2017, 26, 270-276. [CrossRef]

28. Gionco, C.; Battiato, A.; Vittone, E.; Paganini, M.C.; Giamello, E. Structural and spectroscopic properties of high temperature prepared $\mathrm{ZrO}_{2}-\mathrm{TiO}_{2}$ mixed oxides. J. Solid State Chem. 2013, 201, 222-228. [CrossRef]

29. Yuan, Q.; Liu, Y.; Li, L.-L.; Li, Z.-X.; Fang, C.-J.; Duan, W.-T.; Li, X.-G.; Yan, C.-H. Highly ordered mesoporous titania-zirconia photocatalyst for applications in degradation of rhodamine-B and hydrogen evolution. Microporous Mesoporous Mater. 2009, 124, 169-178. [CrossRef]

30. Basahel, S.N.; Ali, T.T.; Mokhtar, M.; Narasimharao, K. Influence of crystal structure of nanosized $\mathrm{ZrO}_{2}$ on photocatalytic degradation of methyl orange. Nanoscale Res. Lett. 2015, 10, 73. [CrossRef]

31. Aflaki, M.; Davar, F. Synthesis, luminescence and photocatalyst properties of zirconia nanosheets by modified Pechini method. J. Mol. Liq. 2016, 221, 1071-1079. [CrossRef]

32. Reddy, V.R.; Hwang, D.W.; Lee, J.S. Photocatalytic water splitting over $\mathrm{ZrO}_{2}$ prepared by precipitation method. Korean J. Chem. Eng. 2003, 20, 1026-1029. [CrossRef]

33. Gionco, C.; Paganini, M.C.; Giamello, E.; Burgess, R.; Di Valentin, C.; Pacchioni, G. Cerium-doped zirconium dioxide, a visible-light-sensitive photoactive material of third generation. J. Phys. Chem. Lett. 2014, 5, 447-451. [CrossRef] [PubMed]

34. Gionco, C.; Paganini, M.C.; Chiesa, M.; Maurelli, S.; Livraghi, S.; Giamello, E. Cerium doped zirconium dioxide as a potential new photocatalytic material. the role of the preparation method on the properties of the material. Appl. Catal. A Gen. 2015, 504, 338-343. [CrossRef]

35. Wang, X.; Wu, Z.; Wang, Y.; Wang, W.; Wang, X.; Bu, Y.; Zhao, J. Adsorption-photodegradation of humic acid in water by using $\mathrm{ZnO}$ coupled $\mathrm{TiO}_{2}$ /bamboo charcoal under visible light irradiation. J. Hazard. Mater. 2013, 262, 16-24. [CrossRef]

36. Oskoei, V.; Dehghani, M.H.; Nazmara, S.; Heibati, B.; Asif, M.; Tyagi, I.; Agarwal, S.; Gupta, V.K. Removal of humic acid from aqueous solution using UV/ZnO nano-photocatalysis and adsorption. J. Mol. Liq. 2016, 213, 374-380. [CrossRef]

37. Wang, G. Destruction of humic acid in water by UV light catalyzed oxidation with hydrogen peroxide. Water Res. 2000, 34, 3882-3887. [CrossRef]

38. Birben, N.C.; Uyguner-Demirel, C.S.; Kavurmaci, S.S.; Gürkan, Y.Y.; Turkten, N.; Cinar, Z.; Bekbolet, M. Application of Fe-doped $\mathrm{TiO}_{2}$ specimens for the solar photocatalytic degradation of humic acid. Catal. Today 2017, 281, 78-84. [CrossRef]

39. Najm, I.N.; Patania, N.L.; Jacangelo, J.G.; Krasner, S.W. Evaluating surrogates for disinfection by-products. J. Am. Water Works Assoc. 1994, 86, 98-106. [CrossRef]

40. Uyguner, C.S.; Bekbolet, M. Evaluation of humic acid photocatalytic degradation by UV-vis and fluorescence spectroscopy. Catal. Today 2005, 101, 267-274. [CrossRef]

41. García-López, E.; Marcì, G.; Pomilla, F.R.; Paganini, M.C.; Gionco, C.; Giamello, E.; Palmisano, L. ZrO 2 Based materials as photocatalysts for 2-propanol oxidation by using UV and solar light irradiation and tests for $\mathrm{CO}_{2}$ reduction. Catal. Today 2018, 313, 100-105. [CrossRef]

42. Hernández, S.; Gionco, C.; Husak, T.; Castellino, M.; Muñoz-Tabares, J.A.; Tolod, K.R.; Giamello, E.; Paganini, M.C.; Russo, N. Insights Into the Sunlight-Driven Water Oxidation by Ce and Er-Doped $\mathrm{ZrO}_{2}$. Front. Chem. 2018, 6. [CrossRef]

43. Sing, K.S.W. Reporting physisorption data for gas/solid systems with special reference to the determination of surface area and porosity (Provisional). Pure Appl. Chem. 1982, 54, 2201-2218. [CrossRef]

44. Wang, D.; Guo, L.; Zhen, Y.; Yue, L.; Xue, G.; Fu, F. AgBr quantum dots decorated mesoporous Bi 2 WO 6 architectures with enhanced photocatalytic activities for methylene blue. J. Mater. Chem. A 2014, 2, 11716-11727. [CrossRef]

45. Nosaka, Y.; Nosaka, A.Y. Generation and Detection of Reactive Oxygen Species in Photocatalysis. Chem. Rev. 2017, 117, 11302-11336. [CrossRef] [PubMed]

46. Ranjan Sahu, H.; Ranga Rao, G. Characterization of combustion synthesized zirconia powder by UV-vis, IR and other techniques. Bull. Mater. Sci. 2000, 23, 349-354. [CrossRef] 
47. Gionco, C.; Paganini, M.C.; Giamello, E.; Burgess, R.; Di Valentin, C.; Pacchioni, G. Paramagnetic Defects in Polycrystalline Zirconia: An EPR and DFT Study. Chem. Mater. 2013, 25, 2243-2253. [CrossRef]

48. Sun, D.D.; Lee, P.F. $\mathrm{TiO}_{2}$ microsphere for the removal of humic acid from water: Complex surface adsorption mechanisms. Sep. Purif. Technol. 2012, 91, 30-37. [CrossRef]

49. Liu, S.; Lim, M.; Amal, R. $\mathrm{TiO}_{2}$-coated natural zeolite: Rapid humic acid adsorption and effective photocatalytic regeneration. Chem. Eng. Sci. 2014, 105, 46-52. [CrossRef]

50. Spark, K.M.; Wells, J.D.; Johnson, B.B. The interaction of a humic acid with heavy metals. Aust. J. Soil Res. 1997, 35, 89. [CrossRef]

51. Kipton, H.; Powell, J.; Town, R.M. Solubility and fractionation of humic acid; effect of $\mathrm{pH}$ and ionic medium. Anal. Chim. Acta 1992, 267, 47-54. [CrossRef]

52. Ferro-García, M.A.; Rivera-Utrilla, J.; Bautista-Toledo, I.; Moreno-Castilla, C. Adsorption of Humic Substances on Activated Carbon from Aqueous Solutions and Their Effect on the Removal of Cr(III) Ions. Langmuir 1998, 14, 1880-1886. [CrossRef]

53. Moussavi, G.; Talebi, S.; Farrokhi, M.; Sabouti, R.M. The investigation of mechanism, kinetic and isotherm of ammonia and humic acid co-adsorption onto natural zeolite. Chem. Eng. J. 2011, 171, 1159-1169. [CrossRef]

54. Coppola, E.; Iovino, P.; Salvestrini, S.; Capasso, S.; Colella, C. Humic acid sorption properties of calcium-rich derivatives of Neapolitan Yellow Tuff. WIT Trans. Ecol. Environ. 2008, 111, 565-574. [CrossRef]

55. Wang, Y.W.; Yuan, P.H.; Fan, C.M.; Wang, Y.; Ding, G.Y.; Wang, Y.F. Preparation of zinc titanate nanoparticles and their photocatalytic behaviors in the photodegradation of humic acid in water. Ceram. Int. 2012, 38, 4173-4180. [CrossRef]

56. Fryxell, G.E.; Cao, G. Environmental Applications of Nanomaterials; Imperial College Press: London, UK, 2012; ISBN 978-1-84816-803-9.

57. Li, X.Z.; Fan, C.M.; Sun, Y.P. Enhancement of photocatalytic oxidation of humic acid in $\mathrm{TiO}_{2}$ suspensions by increasing cation strength. Chemosphere 2002, 48, 453-460. [CrossRef]

58. Xue, G.; Liu, H.; Chen, Q.; Hills, C.; Tyrer, M.; Innocent, F. Synergy between surface adsorption and photocatalysis during degradation of humic acid on $\mathrm{TiO}_{2}$ /activated carbon composites. J. Hazard. Mater. 2011, 186, 765-772. [CrossRef]

59. Subagio, D.P.; Srinivasan, M.; Lim, M.; Lim, T.T. Photocatalytic degradation of bisphenol-A by nitrogen-doped $\mathrm{TiO}_{2}$ hollow sphere in a vis-LED photoreactor. Appl. Catal. B Environ. 2010, 95, 414-422. [CrossRef]

60. Chakrabarti, S.; Dutta, B.K. Photocatalytic degradation of model textile dyes in wastewater using $\mathrm{ZnO}$ as semiconductor catalyst. J. Hazard. Mater. 2004, 112, 269-278. [CrossRef] [PubMed]

61. Guliants, V.V.; Carreon, M.A.; Lin, Y.S. Ordered mesoporous and macroporous inorganic films and membranes. J. Memb. Sci. 2004, 235, 53-72. [CrossRef]

62. Yan, H.; Chai, L.Y.; Peng, B.; Li, M.; Peng, N.; Hou, D.K. A novel method to recover zinc and iron from zinc leaching residue. Miner. Eng. 2014, 55, 103-110. [CrossRef]

63. Juez, R.G.; Boffa, V.; Blank, D.H.A.; ten Elshof, J.E. Preparation of self-supporting mesostructured silica thin film membranes as gateable interconnects for microfluidics. J. Memb. Sci. 2008, 323, 347-351. [CrossRef]

64. Nisticò, R.; Scalarone, D.; Magnacca, G. Sol-gel chemistry, templating and spin-coating deposition: A combined approach to control in a simple way the porosity of inorganic thin films/coatings. Microporous Mesoporous Mater. 2017, 248, 18-29. [CrossRef]

65. Neppolian, B.; Choi, H.C.; Sakthivel, S.; Arabindoo, B.; Murugesan, V. Solar light induced and $\mathrm{TiO}_{2}$ assisted degradation of textile dye reactive blue 4. Chemosphere 2002, 46, 1173-1181. [CrossRef]

66. Rodrigues, A.; Brito, A.; Janknecht, P.; Proença, M.F.; Nogueira, R. Quantification of humic acids in surface water: Effects of divalent cations, pH, and filtration. J. Environ. Monit. 2009, 11, 377-382. [CrossRef] [PubMed]

67. Miyauchi, M.; Nakajima, A.; Watanabe, T.; Hashimoto, K. Photocatalysis and Photoinduced Hydrophilicity of Various Metal Oxide Thin Films. Chem. Mater. 2002, 14, 2812-2816. [CrossRef]

68. Kashif, N.; Ouyang, F. Parameters effect on heterogeneous photocatalysed degradation of phenol in aqueous dispersion of $\mathrm{TiO}_{2}$. J. Environ. Sci. 2009, 21, 527-533. [CrossRef]

69. Guo, Z.; Ma, R.; Li, G. Degradation of phenol by nanomaterial $\mathrm{TiO}_{2}$ in wastewater. Chem. Eng. J. 2006, 119, 55-59. [CrossRef] 
70. Dehghanian, N.; Ghaedi, M.; Ansari, A.; Ghaedi, A.; Vafaei, A.; Asif, M.; Agarwal, S.; Tyagi, I.; Gupta, V.K. A random forest approach for predicting the removal of Congo red from aqueous solutions by adsorption onto tin sulfide nanoparticles loaded on activated carbon. Desalin. Water Treat. 2016, 57, 9272-9285. [CrossRef]

71. Khezrianjoo, S.; Revanasiddappa, H.D. Photocatalytic Degradation of Acid Yellow 36 Using Zinc Oxide Photocatalyst in Aqueous Media. J. Catal. 2013, 2013, 1-6. [CrossRef]

72. Daneshvar, N.; Rasoulifard, M.H.; Khataee, A.R.; Hosseinzadeh, F. Removal of C.I. Acid Orange 7 from aqueous solution by UV irradiation in the presence of ZnO nanopowder. J. Hazard. Mater. 2007, 143, 95-101. [CrossRef] [PubMed]

73. Chen, H.; Motuzas, J.; Martens, W.; Diniz da Costa, J.C. Ceramic metal oxides with Ni $2+$ active phase for the fast degradation of Orange II dye under dark ambiance. Ceram. Int. 2018, 44, 6634-6640. [CrossRef]

74. Calza, P.; Gionco, C.; Giletta, M.; Kalaboka, M.; Sakkas, V.A.; Albanis, T.; Paganini, M.C. Assessment of the abatement of acelsulfame K using cerium doped ZnO as photocatalyst. J. Hazard. Mater. 2017, 323, 471-477. [CrossRef] [PubMed]

75. Thandu, M.; Comuzzi, C.; Goi, D. Phototreatment of Water by Organic Photosensitizers and Comparison with Inorganic Semiconductors. Int. J. Photoenergy 2015, 2015, 1-22. [CrossRef]

76. Hua, Z.; Zhang, X.; Bai, X.; Lv, L.; Ye, Z.; Huang, X. Nitrogen-doped perovskite-type La2Ti2O7decorated on graphene composites exhibiting efficient photocatalytic activity toward bisphenol A in water. J. Colloid Interface Sci. 2015, 450, 45-53. [CrossRef] [PubMed]

77. Zhou, L.; Zou, G.; Deng, H. The Roles of Graphene and Ag in the Hybrid Ag@Ag2O-Graphene for Sulfamethoxazole Degradation. Catalysts 2018, 8, 272. [CrossRef]

78. Tummino, M.L.; Laurenti, E.; Deganello, F.; Bianco Prevot, A.; Magnacca, G. Revisiting the catalytic activity of a doped $\mathrm{SrFeO} 3$ for water pollutants removal: Effect of light and temperature. Appl. Catal. B Environ. 2017, 207, 174-181. [CrossRef]

79. Serpone, N.; Emeline, A.V. Semiconductor photocatalysis-Past, present, and future outlook. J. Phys. Chem. Lett. 2012, 3, 673-677. [CrossRef] [PubMed]

(C) 2019 by the authors. Licensee MDPI, Basel, Switzerland. This article is an open access article distributed under the terms and conditions of the Creative Commons Attribution (CC BY) license (http://creativecommons.org/licenses/by/4.0/). 